CIRJE-F-1097

\title{
Impacts of High-Speed Rail Construction on Urban Agglomerations: Evidence from Kyushu in Japan
}

\author{
Chigusa Okamoto \\ Graduate School of Economics, The University of Tokyo \\ Yasuhiro Sato \\ The University of Tokyo \\ October 2018
}

CIRJE Discussion Papers can be downloaded without charge from:

http://www.cirje.e.u-tokyo.ac.jp/research/03research02dp.html

Discussion Papers are a series of manuscripts in their draft form. They are not intended for circulation or distribution except as indicated by the author. For that reason Discussion Papers may not be reproduced or distributed without the written consent of the author. 


\title{
Impacts of high-speed rail construction on urban agglomerations: Evidence from Kyushu in Japan*
}

\author{
Chigusa Okamoto ${ }^{\dagger}$ and Yasuhiro Sato ${ }^{\ddagger}$
}

October 12, 2018

\begin{abstract}
High-speed rail integrates regions and cities, and thus can possibly have significant impacts on the distribution of economic activities. Using the opening and extensions of a high-speed rail, Shinkansen, in Kyushu, Japan, we examine its effects on the distribution of economic activities across urban agglomerations. We focus on changes in land prices and estimate hedonic price equations to conduct a difference-in-difference analysis. We find that the large metropolitan areas gained from the high-speed rail by experiencing increases in land prices, whereas small metropolitan areas located between them lost by experiencing decreased land prices. However, such positive effects are shown to be limited to areas close to Shinkansen stations.
\end{abstract}

Keywords: High-speed rail, Land price, Hedonic approach, Agglomerations JEL classification: R11, R12, R42

\section{Introduction}

Economic integration is no doubt a major factor shaping economic geography. In addition, railroads have also undoubtedly played a significant role in shaping the economic landscape. In fact, spatial economics literature has often focused on the impacts of decreases in transportation costs on economic geography, and such costs have been lowered by construction of railroad networks. Krugman (1991, page 487, 1.2-1.6) referred to this point as “...let the factory system and

${ }^{*}$ This work was supported by JSPS KAKENHI Grant Numbers 15H03344, 17H02519, and 18H00842. We thank Joshua Angrist, Koichi Fukumura, Atsushi Yamagishi, and participants of seminars held at Tohoku University and University of Tokyo for their helpful comments.

${ }^{\dagger}$ Corresponding author, Graduate School of Economics, University of Tokyo, e-mail: okamotochigusa546@g.ecc.u-tokyo.ac.jp

${ }^{\ddagger}$ Faculty of Economics, University of Tokyo, e-mail: ysato@e.u-tokyo.ac.jp 
eventually mass production emerge, and with them economies of large-scale production; and let canals, railroads, and finally automobiles lower transportation costs. Then, the tie of production to the distribution of land will be broken..." In fact, railroad construction can sometimes change economic geography even over megalopolises. We can find such an example in Japan: it is widely believed that the construction of a high-speed rail, Shinkansen, between the two largest cities in Japan, Tokyo and Osaka, attracted economic activities to Tokyo and caused Osaka's economy to decline. ${ }^{1}$ Until 1960s, Osaka had been Tokyo's rival and had served as the hub of western Japan. However, after the Shinkansen's opening in 1964, many firms shifted their headquarters and substantial amounts of significant functions from Osaka to Tokyo, as indicated by steady outflows of population from the Osaka metropolitan area during the last half century. At present, the new Linear Shinkansen connecting Tokyo and Osaka is under construction and it will open by 2027. This is expected to reduce the travel time between the two cities from 150 minutes to 70 minutes. How and to what degree do such high-speed railways affect the economic geography?

This paper aims to provide clues to answer these questions by quantifying the effects on urban agglomerations of the opening and extension of the high-speed rail in Kyushu, Japan's third largest island. The high-speed rail in Kyushu, called the Kyushu Shinkansen, currently operates in western Kyushu and is called the Kagoshima route. Its southern half opened in 2004 and was extended to the northern half in 2011 to traverse Kyushu longitudinally. Thus, the Kagoshima route of the Kyushu Shinkansen has significantly integrated Kyushu's regions. We examine its impacts on urban agglomerations by quantifying the changes capitalized in land prices. To do so, we estimate hedonic price equations and conduct a difference-in-difference (DID) analysis. We use Urban Employment Areas (UEAs) as the definition of urban agglomerations; UEAs are defined similarly to the Consolidated Metropolitan Statistical Areas and are made from Japanese municipalities (see Kanemoto and Tokuoka, 2002). We construct panel data by using land prices and attributes of locations in Kyushu for 3 years before and after the railway's opening and extension. We then estimate how the opening and extension of the Kagoshima route changed land prices in urban agglomerations.

The estimation results show that the railway's opening and extension have increased land prices greatly in the large metropolitan areas and slightly in their neighboring areas: the opening of the entire Kagoshima route increased land prices in the largest metropolitan area in Kyushu, Fukuoka, by around 16\%, and prices in the second largest metropolitan area, Kumamoto, by around $13 \%$. However, if we extend the estimation by categorizing locations into different

\footnotetext{
${ }^{1}$ See, for example, the PRESIDENT online article (October 30, 2017) by Kenichi Omae: http://president.jp/articles/-/23444 (accessed on February 2, 2018).
} 
groups according to distance to the nearest Shinkansen station, we find such positive effects are limited to areas close to Shinkansen stations. In contrast to these rises, we further find that small metropolitan areas located between large metropolitan areas experienced decreases in land prices. Thus, integration caused by the Kagoshima route has made already-large metropolitan areas larger at the expense of small metropolitan areas.

As recently shown theoretically by Akamatsu et al. (2017), changes in economic geography caused by economic integration crucially depend on the characteristics of the dispersion force. ${ }^{2}$ When dispersion occurs globally through attraction from outside the agglomeration, as in the case of a distant, less-crowded market, integration enlarges already-larger agglomerations at the expense of smaller agglomerations within the integrated regions. Dispersion may also occur locally to avoid crowding inside the agglomeration, as in the case of an urban congestion externality. In such circumstances, integration attenuates agglomeration and makes economic activities dispersed across the integrated regions. Thus, our results are in line with the dominance of the global dispersion force.

Our analysis is related to the literature studying the effect of construction of transportation infrastructure on the location of economic activities. The recent survey of the literature by Redding and Turner (2015) categorized existing studies into two groups: those regarding intracity transportation and those regarding intercity transportation. Our study belongs to the latter category. Most papers in this group have reached a common conclusion that places/agents having good access to the constructed transportation infrastructure gain more than those having poor access. Chandra and Thompson (2000) examined the effect of interstate highway construction in the United States on aggregate annual earnings by county, year and industry. They found that interstate highway construction positively affected treated areas on the whole although some industries were negatively affected. Donaldson (2018) studied the effect of railroad construction in India on the value of agricultural crops. They observed that incomes in treated districts increased by $17 \%$ relative to untreated districts. Donaldson and Hornbeck (2016) studied the effect of rapid rail expansion in the United States and also found that treated counties experienced a huge increase in aggregate agricultural land rent. Finally, Bernard et al. (forthcoming) recently studied the effect of the 2004 partial opening of Kyushu Shinkansen on firms' sales profit. They developed a model where firms can search for suppliers and outsource tasks and the opening of a high-speed rail decreases such search and outsource costs. They tested their theory using data on the partial opening of Kyushu Shinkansen and found that firms located close to the new rail improved their performance significantly.

\footnotetext{
${ }^{2}$ See also Helpman (1998) and Tabuchi (1998).
} 
Although existing studies found that treated places/agents significantly gain from construction of transportation infrastructure, differences in impacts among them have attracted little attention. However, as shown by the literature of spatial economics, construction of transportation infrastructure might have different impacts on connected agglomerations. To the best of our knowledge, our paper is the first empirical effort to delineate such differences. Moreover, land prices are an aggregate of various factors that determine economic agents' location decisions, implying that our analysis can capture the overall effects of construction of high-speed rail on the distribution of economic activities. Regarding the area of our focus, Kyushu has desirable geographic features for program evaluation because the treatment group (here, locations mostly in the western part of Kyushu) and control group (here, locations mostly in the eastern part of Kyushu) had a common trend in land prices before the event. In addition, SUTVA (Stable Unit Treatment Value Assumption) is reasonably satisfied because the two groups are divided by mountains. These features of Kyushu enable us to identify total treatment effects in the western part of Kyushu and analyze heterogeneous treatment effects among agglomerations in the treatment group.

The remainder of this paper is structured as follows. Section 2 describes the details of Kyushu Shinkansen and research background. Section 3 explains our data and section 4 describes our estimation strategies. Section 5 provides the estimation results and section 6 discusses econometric issues. Section 8 concludes.

\section{Research Background}

We first explain the Kagoshima route of Kyushu Shinkansen, which is the focus of this paper, and discuss its possible impacts on urban agglomerations. The Kyushu Shinkansen is a highspeed railway, and its Kagoshima route connects Hakata and Kagoshima-Chuo Stations, which are located in the northern and southern part of Kyushu, respectively. It runs through the western part of Kyushu, with a length of $256.8 \mathrm{~km}$ and stopping at 12 twelve stations (Figure 1).

[Figure 1]

The Kyushu-Shinkansen was constructed and is owned by an Independent administrative agency named the Japan Railway Construction, Transport and Technology Agency, and is operated by 
the Kyushu Railway Company. ${ }^{3}$ As explained by Ministry of Land, Infrastructure, Transport and Tourism (2017), the Kagoshima route project was launched as one of five Shinkansen projects in 1973 based on the Nationwide Shinkansen Railway Development Act. The prerequisites for the project to start were securing a budget for construction, profitability, investment efficiency, and agreements of the Kyushu Railway Company and jurisdictions on the Shinkansen line, all of which were carefully investigated before breaking ground. Construction of the line started in 1991. The southern part of the line (between Shin-Yatsushiro and Kagoshima-Chuo Stations) started operating in March 2004 and the remaining part (between Hakata and Shin-Yatsushiro Stations) commenced operations in March 2011. The former reduced the travel time between Hakata and Kagoshima-Chuo Stations from 3 hours and 40 minutes to 2 hours and 12 minutes, and the latter shortened it to 1 hour and 19 minutes. Overall, the construction of the Kagoshima route decreased the travel time between the two stations by nearly two-thirds.

In this paper, we estimate the effects of the construction of the Kagoshima route of the Kyushu Shinkansen on the local economy, especially on urban agglomerations in Kyushu, by using a hedonic approach a la Rosen (1974). In so doing, we conduct a difference-in-difference estimation using the data for the years 2001 and 2007 (before and after the partial opening), and for 2008 and 2014 (before and after the whole opening). Note here that the project was planned and announced in 1973. However, "the actual construction was subject to substantial timing uncertainty due to numerous budgetary and administrative delays, thus limiting the scope for anticipation effects" (Bernerd et al 2018). Moreover, because the construction started in 1991, we consider that the effects of the project announcement and breaking ground, if any, had already been capitalized at the beginning of operation. Hence, our analysis is able to offer a bottom line of the overall effects of the Kagoshima route construction.

Construction of the Kagoshima route largely decreased the travel time between connected regions. The conventional wisdom of spatial economics holds that such economic integration will significantly affect agglomerations of economic activities (Fujita et al., 2001; Fujita and Thisse, 2013). As recently shown by Akamatsu et al (2017), these effects crucially depend on the characteristics of the dispersion force. When such dispersion occurs globally through attraction from outside the agglomeration, as in the case of a distant, less-crowded market, integration expands the already-larger agglomerations at the expense of smaller agglomerations within integrated regions. When dispersion occurs locally to avoid crowding inside the agglomeration as in the case of an urban congestion externality, integration attenuates agglomeration and leads to economic activities becoming dispersed across the integrated regions. Moreover, the integrated regions as

\footnotetext{
${ }^{3}$ In 1987, the national railway company in Japan was privatized and divided into seven private railway companies, of which the Kyushu Railway Company is one.
} 
a whole can attract economic activities from surrounding non-integrated regions.

Construction of the Kagoshima route is undoubtedly fostering economic integration among regions within Kyushu, especially within its western part, which will significantly affect metropolitan areas in Kyushu. Kyushu is a large island located in the western part of Japan. It has a population of 14.6 million, and has 17 metropolitan areas (MAs) defined by the Metropolitan Employment Areas (MEAs), which will be explained in detail below. Among its 17 MEAs, two are located in the Okinawa prefecture, which, as a remote island prefecture, is much less likely to be affected by construction of the Kagoshima route. Hence, we exclude two MEAs from our analysis. Of the remaining 15 MEAs (Figure 2), six (the Fukuoka, Kurume, Omuta, Kumamoto, Yatsushiro, and Kagoshima MEAs) are located on the Kagoshima route. Accordingly, construction of the Kagoshima route is likely to have especially affected economic integration among these six MEAs. Within the six MEAs, the Fukuoka MEA, which is the largest MEA in Kyushu, is especially large, and the Kumamoto and Kagoshima MEAs are relatively larger than the remaining three MEAs. Hence, it is likely that the three small MEAs will fall into the agglomeration shadows of the three large MEAs to get shrunk in the dominance of the global dispersion force. In contrast, the three small MEAs will enlarge to make the six MEAs more equally sized in the dominance of the local dispersion force. Our analysis uncovers which scenario is relevant to agglomerations in Kyushu. Moreover, the construction of the Kagoshima route attracts economic activities to areas locating on the route from areas not locating on it, implying shrinkage of MEAs not locating on it. We also explore the effects on smaller urban agglomerations defined by the Micropolitan Employment Areas (McEAs), which again will be explained below.

We investigate the impacts of construction of the Kagoshima route on the distribution of economic activities across urban agglomerations by examining changes in land prices. If a particular MEA can attract economic activities due to construction of the Kagoshima route, its land prices will rise. If it loses economic activities, its land prices will decline. The impacts of construction of the Kagoshima route capitalized in land prices are estimated using the hedonic approach a la Rosen (1974) via a difference-in-differences approach. Because the operation of the Kagoshima route occurred in two stages wherein the southern part of the line started operating in 2004 and the remaining part in 2011, we conduct the difference-in-differences for each step. In order to estimate the effects on land prices in MEAs, we set dummies that represent whether a point is located in each MEA. Moreover, in the estimation, we include characteristics of each point as control variables. 


\section{Data}

Data on land prices comes from the Official Announcement of Land Prices published by the Ministry of Land, Infrastructure, Transport and Tourism (MILT). The Land Appraisal Committee of MILT selects a point for the housing site and its respective point in city planning areas, asks two or more real estate appraisers to appraise these points, and judges and publicly announces the proper land price per square meter once a year. ${ }^{4}$ It also describes each point's location, acreage, land-use zoning, building-area ratio, and floor-area ratio. ${ }^{5}$ Note here that land prices used in this paper have been appraised by real estate appraisers and are not transaction prices; although the latter can reflect specific factors about a point that are not explicitly captured by data, the former is standardized regarding such factors across neighborhoods. Because our focus is not on a point's implicit specific factors, we use the former. ${ }^{6}$ Kyushu contains eight prefectures (Fukuoka, Saga, Nagasaki, Kumamoto, Oita, Miyazaki, Kagoshima, and Okinawa). However, because Okinawa is a small isolated island prefecture located extremely distant from the other seven prefectures, we use land price data on other seven prefectures located on the main Kyushu island. Japan as a whole has approximately 26,000 points and the seven Kyushu prefectures have approximately 2,600 thousand points. We estimate the effects of the high-speed railway's partial opening by using data for the years 2001 and 2007, which are 3 years prior to and 3 years after the operation's start, respectively. Similarly, we estimate the effects of the entire opening by using data for the years 2008 and 2014. Each year, MILT replaces some of the points with new ones, and the share of common points between 2001 and 2007 is approximately 0.6 and that between 2008 and 2014 is approximately 0.3. The analysis data include 5,488 samples for the partial opening and 4,740 samples for the whole opening. Table 1 reports the descriptive statistics of the analysis sample.

[Table 1]

For the metropolitan areas, we used the Urban Employment Areas (UEAs), which are defined similarly to the Consolidated Metropolitan Statistical Areas and derived from Japanese municipalities (see Kanemoto and Tokuoka 2002). We use the UEAs based on the 2010 Population Census of Japan. ${ }^{7}$ A UEA having the densely inhabited district (DID) population larger than

\footnotetext{
${ }^{4}$ It appraises the points as of January 1 and announces prices in late March every year.

${ }^{5}$ Information on the last two are available if the point is located in the town planning area.

${ }^{6}$ Land transaction prices are available in the Land General Information System maintained by MILT.

${ }^{7}$ During the periods of our focus, we experienced a large number of municipality mergers. For our analysis, we converted the municipality information of the standard points into the one observed on October 1, 2010.
} 
50,000 in the central city is called a Metropolitan Employment Area (MEA), and one having the DID population of 10,000-50,000 in the central city area is called a Micropolitan Employment Area (McEA). Figure 2 (resp. Figure 3) is a map of the MEAs (resp. McEAs) in Kyushu and the Kagoshima route of Kyushu Shinkansen. Table 2 and Table 3 summarize the characteristics of MEAs/McEAs in Kyushu in terms of population, natural environment and economic base. Because detailed addresses for the points are available, we can identify whether a particular point is located within the areas of any UEA, and make a dummy that takes one if it is located within a particular UEA. The area of our focus has 15 MEAs and 22 McEAs. In the first step of constructing the Kagoshima route, the line passed two MEAs (Yatsushiro and Kagoshima) and two McEAs (Minamata and Satsumakawachi) located on the line, whereas in the second step, it passed additional four MEAs (Fukuoka, Kurume, Omuta, and Kumamoto) and two McEAs (Tosu and Tamana).

[Figure 2, Figure 3, Table 2 and Table 3]

In order to identify the areas impacted by the construction of the Kagoshima route, we also use data on a point's distance to its nearest Shinkansen station on the Kagoshima route. ${ }^{8}$ The MILT provides geographical data on the railroad network for the year 2015, which, combined with the address information of points, we used to compute the linear distance between each point and its nearest Shinkansen station on the Kagoshima route. For the partial opening of the Kagoshima route, we derived the distance to the nearest station for those from Shin-Yatsushiro to Kagoshima-Chuo Stations, and for the whole opening, we derived the distance to the nearest station for those from Hakata to Kagoshima-Chuo Stations.

\section{Econometric Specification}

This paper uses the difference-in-differences approach to uncover the impacts of construction of the Kagoshima route on urban agglomerations. For each step of the route's construction, we estimate three specifications. The first specification examines the impacts on urban agglomerations as a whole. The second one investigates differences in the impacts among agglomerations that have at least one Shinkansen station. The last one explores the impacts on each urban agglomeration more in detail. In all specifications in each step, we use data for 3 years before and 3 years after the operation's start. In all estimations, the dependent variable is $\ln \left(p_{i j t}\right)$,

\footnotetext{
${ }^{8}$ In computing distances, we use the geodist command available in Stata.
} 
which denotes the logarithm of land price of point $i$ located in municipality $j$ at time $t$. We denote the after-treatment dummy by $w_{t}$, the point $i$ 's attribute vector by $X_{i t}$, the time-invariant unobserved characteristics of municipality $j$ by $c_{j}$, the year dummy by $p_{t}$, and the idiosyncratic error term by $u_{i j t}$. Because the operation of the Kagoshima route occurred in two steps, $w_{t}$ takes zero if $t=2001$ and one if $t=2007$ for the partial opening, and zero if $t=2008$ and one if $t=2014$ for the whole opening. $X_{i t}$ includes the distance from the nearest train station, building-area ratio, floor-area ratio, acreage, land-use zoning dummies (no regulation/residential purpose/commercial purpose/industrial purpose), town planning area dummy and supply system dummies (water/gas/drain). ${ }^{9}$

In the first specification, which we call Analysis 1, we aim to estimate the impacts on urban agglomerations as a whole. We specify the estimation equation as

$$
\ln \left(p_{i j t}\right)=\alpha+\beta_{\text {mea }} w_{t} \sum_{l=1}^{L} Z_{j, l}+\beta_{\text {mcea }} w_{t} \sum_{s=1}^{S} Z_{j, s}+X_{i t} \gamma+c_{j}+p_{t}+u_{i j t},
$$

where $l$ and $s$ represent the MEA and McEA, respectively, and $Z_{j, l}$ (resp., $Z_{j, s}$ ) is the dummy that takes one if municipality $j$ is included in MEA $l$ (resp., McEA $s$ ) and zero otherwise. Hence, $\sum_{l=1}^{L} Z_{j, l}$ (resp., $\sum_{s=1}^{S} Z_{j, s}$ ) takes one if municipality $j$ is included in any MEA (resp., McEA). Our DID estimators are $\beta_{m e a}$ and $\beta_{\text {mcea }}$ : if the estimated $\beta_{\text {mea }}$ (resp., $\beta_{\text {mcea }}$ ) is positive, construction of the Kagoshima route has boosted land prices in MEAs (resp., McEAs) in Kyushu.

Note here that identification of the DID estimator requires no correlation between the independent variable related to the DID estimator and error term. However, as explained by Ministry of Land, Infrastructure, Transport and Tourism (2017), profitability and investment efficiency are required the construction of the Shinkansen, implying that the location choice for the Shinkansen might possibly relate to time-invariant unobserved characteristics. In order to control for such a correlation, we included a fixed effect for each municipality, $c_{j}$, in the estimation equation.

In the second specification, which we call Analysis 2, we extend the first specification to examine differences in the impacts among urban agglomerations that have at least one Shinkansen station. We specify the estimation equation as

$$
\ln \left(p_{i j t}\right)=\alpha+\sum_{l=1}^{L} \beta_{l^{*}} w_{t} Z_{j, l^{*}}+\sum_{s=1}^{S} \beta_{s} w_{t} Z_{j, s^{*}}+X_{i t} \gamma+c_{j}+p_{t}+u_{i j t},
$$

where $l^{*}$ and $s^{*}$ represent the MEA and McEA that have at least one Shinkansen station, respectively. $Z_{j, l^{*}}$ (resp., $Z_{j, s^{*}}$ ) is the dummy that takes one if municipality $j$ is included in MEA $l^{*}$ (resp., McEA $s^{*}$ ) and zero otherwise. Note here that we estimate the DID estimators

\footnotetext{
${ }^{9}$ The distance from the nearest train station is calculated by road distance.
} 
$\beta_{l^{*}}$ and $\beta_{s^{*}}$ for each MEA and McEA, respectively. This reflects our idea that the impacts might differ depending on the location of the MEA/McEA along the route.

In the last specification, which we call Analysis 3, we look in greater detail at the impacts on each urban agglomeration by using data on linear distance between the point and the nearest Shinkansen station on the Kagoshima route. For this purpose, we categorize the points into six groups according to their distance to the nearest Shinkansen station. Each category has a range of $5 \mathrm{~km}$, i.e., the first category consists of points with a distance shorter than $5 \mathrm{~km}$, the second category consists of those with the distance equal to or greater than $5 \mathrm{~km}$ and less than $10 \mathrm{~km}$, and so on, such that the final (6th) category consists of those with a distance equal to or greater than $25 \mathrm{~km}$. Letting $D_{d, i}$ denote the dummy that takes one if point $i$ is included in category $d$ and zero otherwise, we specify the estimation equation as

$$
\ln \left(p_{i j t}\right)=\alpha+\sum_{d=1}^{5} \beta_{d} w_{t} D_{d, i}+\sum_{d=1}^{5} \sum_{l=1}^{L} \beta_{d, l} w_{t} D_{d, i} Z_{j, l}+\sum_{d=1}^{5} \sum_{s=1}^{S} \beta_{d, s} w_{t} D_{d, i} Z_{j, s}+X_{i t} \gamma+c_{j}+p_{t}+u_{i j t}
$$

where $l$ and $s$ represent the MEA and McEA. Again, $Z_{j, l}$ (resp., $Z_{j, s}$ ) is the dummy that takes one if municipality $j$ is included in MEA $l$ (resp., McEA $s$ ) and zero otherwise. Because the DID estimator $\beta_{d, l}$ and $\beta_{d, s}$ now depend on the distance to the nearest Shinkansen station, this specification allows us to uncover the different impacts on locations within each MEA/McEA.

\section{$5 \quad$ Estimation Results}

\subsection{Analysis 1}

Table 4 presents the estimation results of the first specification (1).

[Table 4]

In this analysis, we examine the impacts on urban agglomerations as a whole by estimating $\beta_{\text {mea }}$ and $\beta_{\text {mcea }}$ for each step of construction of the Kagoshima route. Columns (1)-(3) show the results for the partial route's opening in 2004 and columns (4)-(6) show the results for the whole opening in 2011. In columns (1) and (4) (resp., columns (2) and (5)), we include only the DID estimator for the MEAs (resp., the McEAs) whereas columns (3) and (6) include the DID estimator for the MEAs and McEAs. The signs of the estimated coefficients for control variables are as expected, and we omit them from Table 4 because they do not fall within our 
focus. ${ }^{10}$ In columns (3a) and (6a), DID estimators are for MEAs and McEAs that have at least one station along the Kagoshima route.

\section{Partial Opening of the Kagoshima route}

In columns (1) and (3), the DID estimator for the MEAs as a whole $\left(\beta_{\text {mea }}\right)$ is negative and significant. For the McEAs, the DID estimator $\left(\beta_{\text {mcea }}\right)$ is positive and significant in column (2). However, once we control for the effect of the opening of the MEAs, it becomes insignificant, as shown in column (3). Moreover, if we focus on MEAs and McEAs that have stations along the Kagoshima route, the DID estimator for the MEAs becomes positive, but that for the McEAs remains insignificant, as shown in column (3a). These results imply that the economic activities were attracted to MEAs having stations along the Kagoshima route from those not having stations along the Kagoshima route, resulting in increases in land prices in the former and price decreases in the latter. Overall, the latter effect dominated the former effect, and the partial opening of the Kagoshima route decreased land prices of the MEAs by an average of around $11 \%$ whereas it affect that of the McEAs only insignificantly.

\section{Opening of the entire Kagoshima route}

In contrast to the partial opening, the DID estimators for the MEAs at the opening of the entire route are positive and significant, as shown in columns (4), (6), and (6a). The opening of the whole Kagoshima route raised land prices in the MEAs in Kyushu on average by around 8.6\%. Regarding the McEAs, the estimated coefficient is negative and significant, as shown in column (5). However, once the effect of the opening on the MEAs is controlled, the estimated coefficient becomes insignificant, as shown in columns (6) and (6a). In short, the opening of the entire route in 2011 attracted economic activities to the urban agglomerations, especially to MEAs.

In the analysis of the opening of the entire route, one concern is the effect of the global financial crisis in 2008. Because it is included in our analysis period, the estimation results may include the crisis's effect on land prices. In order to eliminate this effect, we replace data for the year 2008 with data for the year 2009 in columns (7) and (7a). Although the absolute values of the estimated coefficients for MEAs become slightly smaller compared with those in columns (6) and (6a), the significance of the coefficients does not change, which implies that the global financial crisis was not responsible for the results for the opening of the whole route.

\footnotetext{
${ }^{10}$ The results for control variables are provided in Appendix A.
} 


\subsection{Analysis 2}

Results of Analysis 1 (columns (3) and (3a) of Table 4) show that the impacts of construction of the Kagoshima route can differ between urban agglomerations having stations on the Kagoshima route and those that lack such a station. In the second analysis, we try to exploit such differences more in detail. Table 5 shows the estimation results of the second specification (2).

\section{[Table 5]}

The DID estimators are $\beta_{l^{*}}$, and $\beta_{s^{*}}$. In addition, $\beta_{l^{*}}$ and $\beta_{s^{*}}$ are the DID estimator for each MEA/McEA that has stations on the Kagoshima route. Columns (1)-(3) show the results for the partial opening in 2004 and columns (4)-(6) show the results for the entire route's opening in 2011. Columns (1) and (4) (resp., columns (2) and (5)) include only the DID estimators for the MEAs (resp., those for the McEAs), and columns (3) and (6) includes both. ${ }^{11}$

\section{Partial opening of the Kagoshima route}

After the partial opening, the Shinkansen passed through two MEAs (Kagoshima and Yatsushiro) and two McEAs (Minamata and Satsumasendai). Columns (1) and (3) show the DID estimator for MEAs having stations along the Kagoshima route. Turning to the MEAs on the Kagoshima route, the estimated coefficient for the Kagoshima MEA is positively significant and its value is 0.132 , implying that land prices in the Kagoshima MEA increased by $13.2 \%$. On the contrary, the estimated coefficient for the Yatsushiro MEA is negative and significant, and its value is around -0.08 , implying that land prices in this MEA decreased by $8 \%$.

The results for the McEAs having stations on the Kagoshima route are shown in columns (2) and (3). The estimated coefficient for the Minamata McEA is negative and significant. As seen in column (3), the McEA experienced changes in land price by $-5.5 \%$, which is slightly smaller in magnitude than the changes in the neighboring MEA, i.e., Yatsushiro MEA. The estimated coefficient for Satsumasendai McEA is statistically insignificant or weakly significant. If we take the figure in column (3), the McEA experienced land price rises of $4.8 \%$. In total, the partial opening attracted economic activities to the Kagoshima MEA from other MEAs (especially from Yatsushiro MEA and its neighboring McEA). Because the Kagoshima MEA is the largest urban agglomeration among those on section of the Kagoshima route operative in 2004, the partial opening of the Kagoshima route expanded the already-large urban agglomeration at the expense of other smaller urban agglomerations, especially those on the route. Thus, our results here is in line with the view of the global dispersion force a la Akamatsu et al (2017).

\footnotetext{
${ }^{11}$ Again, the results for control variables are as expected and are provided in Appendix A.
} 


\section{Opening of the entire Kagoshima route}

After the opening of the entire route, the Shinkansen traveled through four other MEAs (Fukuoka, Kurume, Omuta, and Kumamoto) and two McEAs (Tosu and Tamana), each of which has at least one station on the route. Columns (4) and (6) show the DID estimator for MEAs. The estimated coefficients of the DID estimators are positive and significant for the larger MEAs (Fukuoka and Kumamoto). The Fukuoka MEA, the largest MEA, had the largest coefficient of 0.105 , indicating that land prices rose by $10.5 \%$. The Kumamoto MEA, the second largest MEA, followed the Fukuoka MEA with a coefficient of 0.077 , indicating a $7.7 \%$ increase in land prices. The estimated coefficients of the DID estimators are negative and significant for smaller MEAs (Omuta and Yatsushiro). The Yatsushiro MEA has a coefficient of -0.066, implying that land prices in this MEA decreased by $6.6 \%$. The estimated coefficient for the Omuta MEA are statistically insignificant. The estimated coefficients for the intermediate-size MEAs (Kurume and Kagoshima MEAs) are significantly positive. Those MEAs saw increases in land prices by $5.6 \%$ and $7.0 \%$, respectively. The DID estimator for McEAs are provided in columns (5) and (6), where it can be seen that the estimated coefficients for the McEAs are not very significant.

Thus, we can conclude that the opening of the entire route attracted economic activities to large urban agglomerations (i.e., MEAs) on average, and drastically changed the distribution of economic activities among the MEAs having stations along the route: larger MEAs gained and smaller MEAs lost. In contrast, it affected small urban agglomerations (i.e., McEAs) only insignificantly. The insignificant effects on McEAs might be due to two counterbalancing forces. On one hand, the whole opening moved economic activities to large MEAs from other areas including McEAs. On the other hand, it attracted economic activities from outside of Kyushu. These two forces could possibly offset each other, yielding insignificant results.

In order to eliminate the effect of the financial crisis, we again replace data for the year 2008 with data for the year 2009 in column (7) of Table 5. Although the absolute value of the estimated coefficients for MEAs become slightly smaller compared with those in column (6), the significance of the coefficients does not change, which implies that the global financial crisis is not responsible for the results for the whole route's opening.

\subsection{Analysis 3}

In the third analysis, we examine the effects on each urban agglomerations more in detail by focusing on the distance of each point from the nearest Shinkansen station. Tables 6-8 provides the estimation results of the third specification (3). 
[Tables 6,7 and 8$]$

Here, the DID estimators are $\beta_{d, l}$ and $\beta_{d, s}$, where the subscript $d$ represents the category for distance from the nearest Shinkansen station. We set six distance categories from the nearest Shinkansen station: $0-5 \mathrm{~km}, 5-10 \mathrm{~km}, 10-15 \mathrm{~km}, 15-20 \mathrm{~km}, 20-25 \mathrm{~km}$, and over $25 \mathrm{~km}$. Tables 4 and 5 show the estimated coefficients for the partial opening and entire opening, respectively. In these tables, a star indicates that the MEA/McEA has stations on the Kagoshima route. Hence, in Table 6, only two MEAs and two McEAs have star, whereas in Table 7, six MEAs and four McEAs have one. In both tables, the first line shows the estimated $\beta_{d}$, which represents the effects on land prices of the distance between a point and the nearest Shinkansen station regardless of the point being included in a MEA/McEA.

\section{Partial opening of the Kagoshima route}

Table 6 shows the estimation results of Analysis 3 for the partial opening. The estimated coefficient on a dummy representing the distance category $d$ regardless of a point being included in a MEA/McEA, $\beta_{d}$, is strongly significant for categories $0-5 \mathrm{~km}, 5-10 \mathrm{~km}$, and $10-15 \mathrm{~km}$, taking a value of $-0.093,0.209$, and 0.463 , respectively. Overall, the construction of the Kagoshima route attracted economic activities to areas close to Shinkansen stations from more distant areas. However, such areas must compete with the large MEA on the route, Kagoshima MEA, for economic activities. The decreases in land prices in the $0-5 \mathrm{~km}$ would reflect the dominance of the latter negative effect, whereas the increases in land prices for $5-10 \mathrm{~km}$ and $10-15 \mathrm{~km}$ categories would reflect the dominance of the former positive effect.

For the Yatsushiro MEA, the coefficients for $0-5 \mathrm{~km}, 5-10 \mathrm{~km}$ and $10-15 \mathrm{~km}$ distance categories are negative and significant, taking a value of $-0.096,-0.457$, and -0.461 respectively. Hence, areas closest to the Shinkansen station $(0-5 \mathrm{~km})$ saw land prices drop by around $18.9 \%$. For the Minamata McEA, which is close to the Yatsushiro MEA, a distance category exists only for $0-5 \mathrm{~km}$ and its estimated coefficient is -0.065 ; this is significant, implying decreases in land prices by around $15.8 \%$.

Inside the Kagoshima MEA, only the 0-5km areas saw land prices increase; other areas experienced decreases. Although the Kagoshima MEA as a whole has attracted economic activities, areas within the MEA that have attracted such activities are limited, and they are relatively close to the Shinkansen station. For areas distant from a Shinkansen station by more than $25 \mathrm{~km}$, land prices have declined dramatically. For the Satsumasendai McEA, which is close to the Kagoshima MEA, land prices increased only in the $5-10 \mathrm{~km}$ category. Similar to the Kagoshima MEA, areas that attracted economics activities inside the McEA are limited. 
Regarding MEAs/McEAs that are not located on the Kagoshima route, the Kumamoto MEA experienced increases in land prices for the $10-15 \mathrm{~km}$ category. This would reflect the people's expectation that the Shinkansen will reach the Kumamoto MEA in the near future. There exist other MEA/McEAs (Nobeoka MEA, Shimabara McEA, Yamaga McEA, and Hyuga McEA) that experienced land price rises. Such MEAs/McEAs are close to either the Kumamoto MEA or Kagoshima MEA.

\section{Opening of the entire Kagoshima route}

Table 7 presents the estimation results of Analysis 3 for the opening of the whole route. Again, $\beta_{d}$, which is the estimated coefficient on a dummy representing the distance category $d$, regardless of a point being included in a MEA/McEA is statistically significant for areas close to Shinkansen stations, negative for the closest category $(-0.056$ for $0-5 \mathrm{~km})$, and positive for the next closest category $(0.281$ for $5-10 \mathrm{~km})$. Similar to the case of partial opening, the positive effect can be attributed to the attraction of economic activities from areas distant from the Kagoshima route, and the negative effect reflects competition with large MEAs along the Kagoshima route, namely the Fukuoka, Kumamoto, and Kagoshima MEAs. Overall, the negative effect dominates for the closest category, whereas the positive effect dominates for the next closest category.

We can see strong positive and significant effects on land prices for the 0-5km category in the Fukuoka, Kumamoto, and Kagoshima MEAs. The estimated values for the 0-5km category are 0.424 for the Fukuoka MEA, 0.275 for the Kumamoto MEA, and 0.415 for the Kagoshima MEA, resulting in land price increases of $36.8 \%, 21.9 \%$, and $35.9 \%$, respectively. However, such positive effects become weaker with distance to a Shinkansen station, and in the Kumamoto and Kagoshima MEAs, the effects become even negative and significant for areas distant from a Shinkansen station.

These positive effects propagate to the MEAs and McEAs close to the Fukuoka, Kumamoto, and Kagoshima MEAs (i.e., Omuta and Kurume MEAs and Tosu McEA, which are close to the Fukuoka MEA, Tamana McEA, which is close to the Kumamoto MEA, and Satsumasendai McEA, which is close to the Kagoshima MEA), and the effects are positive and significant for areas close to the Shinkansen stations in these urban agglomerations. However, again, the positive effects are limited to areas close to Shinkansen stations, and they turn to be negative or insignificant as distance to a Shinkansen station increases. In addition, some MEAs and McEAs experienced increases in land prices although they are located far from Shinkansen stations. This implies that the opening of the entire Kagoshima route attracted economic activities to Kyushu as a whole from outside. In contrast, the Yatsushiro MEA experienced large decreases 
$(-26.0 \%)$ in land prices for the $5-10 \mathrm{~km}$ category.

We can summarize our findings as follows. First, the opening of the entire Kagoshima route attracted economic activities to Kyushu from outside the region. Second, within Kyushu, it attracted economic activities to areas close to the Kagoshima route. Finally, such attractions served to make already-large urban agglomerations even larger. Hence, overall, our results are in line with the view of the global dispersion force a la Akamatsu et al (2017). However, at the local scale, we observe propagation of the positive effects on land prices from large MEAs to small surrounding MEAs/McEAs, indicating existence of a local dispersion force.

In order to eliminate the effect of the financial crisis, we again replace data for the year 2008 with data for the year 2009 in Table 8. We obtain very similar results to those shown in Table 5, which implies that the global financial crisis is not responsible for the results from the opening of the entire route.

\section{$6 \quad$ Econometric Issues}

\subsection{Placebo Test}

In order to check if the treatment and control groups share common time trends in land prices before the construction of Shinkansen, we implement placebo tests. For the placebo test regarding the partial opening in 2004, we use data for the years 1994 and 2000 as if the partial opening had occurred at the beginning of 1997. Similarly, for the test regarding the whole opening in 2011, we use data for the years 2002 and 2008 as if the whole opening had occurred at the beginning of 2005. The following results imply that the common trend assumption cannot be rejected.

Table 9 shows the results of estimating the same specification as those shown in columns (1) - (6a) in Table 4 (i.e., Analysis 1).

[Table 9]

From Table 9, we know that the DID estimators of the MEAs and the McEAs are insignificant for both the partial opening and the entire opening. Hence, we cannot reject the null hypothesis that the treatment and control groups have same time trends in land prices.

The common trend assumption can be verified also by Figure 4, which shows the average land prices in treatment and control groups. Here, the treatment group includes points in any MEAs/McEAs that have stations on the Kagoshima route after the opening of the entire route, 
and the control group includes the remaining points. The red vertical line on the left shows the year of the partial opening (2004) and the red vertical line on the right shows the year of the entire opening (2011). Before 2004, both treatment and control groups have declining trends in land prices, and they moved in parallel. After 2004 (i.e., after the partial opening), only the treatment group experienced increased in land prices.

[Figure 4]

\subsection{Sub-sample analysis by land-use zoning}

Japan uses land-use zoning as a part of its urban land-use planning system, which is implemented by local municipalities under the City Planning Law. Twelve categories of land use zones are defined, and each of them specifies the use of buildings that are allowed to be constructed in a zone. These categories can be generally divided into three groups: residential, commercial, and industrial uses. In this subsection, we construct three sub-samples, each of which corresponds to one group, and conduct analyses with specifications (1) and (2) for each sub-sample. ${ }^{12}$ This enables us to study which types of location have been more intensively affected by construction of the high-speed railway.

Table 10 shows the estimation results of the first specification (1). Here, we estimate the DID estimators of MEA/McEA having stations on the Kagoshima route. Columns (1)-(4) show the results for the partial opening in 2004 and columns (5)-(8) show the results for the opening of the entire route in 2011. Columns (1) and (5) are the baseline results that come from columns (3a) and (6a) in Table 4. Columns (2), (3), and (4) (and columns (6), (7), and (8)) show the results of sub-sample analyses for residential, commercial, and industrial uses, respectively.

\section{[Table 10]}

For the partial opening in 2004, the DID estimators are significantly positive only for the residential use; surprisingly they are insignificant for the commercial use. This findings implies that the partial opening positively affected land prices in residential areas but not in commercial areas. On the other hand, the opening of the entire route in 2011 increased land prices in both residential and commercial areas. The estimated increases are similar between these two types of land uses, taking values of around $6.6 \%$.

\footnotetext{
${ }^{12}$ Although each specification shown in Section 5 includes land-use zoning dummies, they are omitted in this section.
} 
Why did the partial opening have an insignificant effect on commercial areas insignificantly? We offer two possibilities. First, it is possible that land prices in commercial areas had responded earlier than the actual opening. The historical trends in Japanese land prices show that land prices in commercial areas have responded to events such as the "bubble economy" more quickly than land prices in residential areas (Sato, 2014). Because people expected the opening of the Kagoshima route, land prices in commercial areas might have increased prior to the opening in 2004. Thus, the estimated impact shown in column (1) in Table 10 may be biased downward compared with the actual impact. Second, the effects of firm sorting might be responsible for the insignificance. The partial opening could have intensified competition among firms, as shown by Melitz (2003), forcing firms with lower productivity to exit the market and enabling firms with higher productivity to make higher profits. Such a sorting effect might be responsible for the unclear effect on commercial land prices. In contrast, such competition does not exist in residential areas, resulting in significantly positive DID estimators. This possibility is consistent with the findings of Bernard et al. (2018) that the partial opening of the Kagoshima route increased firms' sales prices.

Table 11 presents the results of sub-sample analyses under the second specification (2). Again, columns (2)-(4) (resp., columns (6)-(8)) show the results for the partial opening (resp. the entire opening) for residential, commercial, and industrial areas, respectively. Columns (1) and (5) are the baseline results that come from columns (3) and (6) in Table 5.

\section{[Table 11]}

For the partial opening in 2004, signs on the estimated coefficients are almost the same across columns (1)-(3). However, significant increases in land prices were observed only in residential areas of the Kagoshima MEA and Satsumasendai McEA. In contrast, the significant decreases in land prices were observed only in commercial areas of the Yatsushiro MEA. These results imply that the partial opening induced residents to move toward larger MEAs/McEAs and firms to leave smaller MEAs. For the entire route's opening in 2011, although signs of the DID estimators are again almost the same across columns (5)-(8), their significance varies. For residential areas (column (6)), only MEAs having stations on the Kagoshima route experienced significant impacts, which were positive for relatively larger MEAs such as Fukuoka and Kumamoto MEAs, and negative for relatively smaller MEAs such as Omuta and Yatsushiro MEAs. These results imply that the opening of the entire route induced residents to move from smaller to larger agglomerations. For commercial areas (column (7)), three largest MEAs, i.e., Fukuoka, Kumamoto, and Kagoshima MEAs, and McEAs close to these MEAs such as Tosu and 
Minamata McEAs experienced significant positive impacts, implying that firms are attracted to larger MEAs and their neighborhoods by the opening of the entire route.

\subsection{Dynamic effects}

It is possible that the impacts of high-speed rail construction emerge gradually. To capture such a process, we conduct the difference-in-difference estimation using multiple treatment periods. We use land price data for 5 years before and after each event: we use data from 2000 to 2009 for the partial opening and data from 2007 to 2016 for the entire opening. We modify the first specification (1) as

$$
\ln \left(p_{i j t}\right)=\alpha+\sum_{t=1}^{T} \beta_{\text {mea }, t} \sum_{l=1}^{L} Z_{j, l}+\sum_{t=1}^{T} \beta_{\text {mcea }, t} \sum_{s=1}^{S} Z_{j, s}+X_{i t} \gamma+c_{j}+p_{t}+u_{i j t},
$$

where $t \in\{0,1, \ldots, T\}$ represents year. DID estimators $\left(\beta_{\text {mea }, t}\right.$ and $\left.\beta_{\text {mcea,t }}\right)$ are the coefficients of year dummies multiplied by the MEAs/McEAs dummy. We exclude the first year of each data from the year dummies to avoid collinearity. Thus, we estimate nine $\beta_{\text {mea,t }}$ and nine $\beta_{\text {mcea,t }}$ for each event, where the years 2000 and 2007 are the base years for the partial opening and the entire opening, respectively. Note here that land prices are evaluated on January 1st of each year in our data, and the day of the partial opening was March 13, 2004, and that of entire opening was March 12, 2011 Hence, $\beta_{\text {mea,2004 }}, \beta_{\text {mcea,2004 }}, \beta_{\text {mea,2011 }}$ and $\beta_{\text {mcea,2011 }}$ show the effects on land prices before the event.

Table 12 presents the results. For the partial opening in 2004, the DID estimators of MEAs are significantly positive throughout the period. The estimator values are small before the opening. This implies that land prices in MEAs increased compared with prices in 2000 even before the partial opening. This could be due to early responses of commercial land prices as we discussed in Section 6.2. After the partial opening, the values of estimators gradually increased. This result also implies that the effect of the partial opening was not a temporary shock but a persistent one. In contrast, the DID estimators of McEAs are significant only for 2003 and 2004. This finding may reflect the early responses of commercial land prices, similar to the case of MEAs. However, we observe no significant effects on land prices in McEAs after the event. For the opening of the entire route in 2011, the DID estimators of MEAs before the event are insignificant or only weakly significant. This result shows that the common trend assumption is satisfied for the opening of the entire route. After the event, they are significantly positive and the impacts continue to increase until the end of the period. We observe insignificant effects on McEAs throughout the periods. 
[Table 12]

\subsection{Equilibrium effects}

The opening and extension of the Kagoshima route induced people and firms to move to agglomerations containing a Shinkansen stations from those without a station. This increased land demand and land prices in the former, implying that after the event, the positive slope of the hedonic curve on land price becomes steeper. Kuminoff and Pope (2014) showed that such an equilibrium effect can be a source of bias in DID estimation. In our analyses, we used the specifications wherein the marginal willingness to pay for land in agglomerations with Shinkansen stations is constant over time. We here follow Kawaguchi and Yukutake (2017) in considering the equilibrium effects and alter the first specification (1) as

$$
\begin{aligned}
& \ln \left(p_{i j 0}\right)=\alpha+\beta_{\text {mea }, 0}\left(\mathrm{MEA}_{0}\right)+\beta_{\text {mea }, 0}\left(\mathrm{McEA}_{0}\right)+X_{i 0} \gamma+c_{j}+p_{0}+u_{i j 0}, \\
& \ln \left(p_{i j 1}\right)=\alpha+\beta_{\text {mea }, 1}\left(\mathrm{MEA}_{1}\right)+\beta_{\text {mea }, 1}\left(\mathrm{McEA}_{1}\right)+X_{i 1} \gamma+c_{j}+p_{1}+u_{i j 1},
\end{aligned}
$$

where the subscript 0 represents the period before the opening and subscript 1 represents the period after the opening. "MEA" and "McEA" are dummies for MEAs and McEAs with Shinkansen stations, respectively, implying that $\beta_{m e a, t}$ and $\beta_{m c e a, t}$ represent the marginal willingness to pay for land in MEAs and McEAs with Shinkansen stations at time $t(t=0,1)$, respectively. Note here that we assume that the opening and extension did not change the unit price of land characteristics, keeping $\gamma$ constant over the periods. If we take the difference of these equations, we obtain the first-difference equation as

$$
\begin{aligned}
\Delta l n\left(p_{i j}\right) & =\beta_{\text {mea }, 1} \Delta \mathrm{MEA}+\left(\beta_{\text {mea }, 1}-\beta_{\text {mea }, 0}\right) \mathrm{MEA}_{0} \\
& +\beta_{\text {mcea }, 1} \Delta \mathrm{McEA}+\left(\beta_{\text {mcea }, 1}-\beta_{\text {mcea }, 0}\right) \mathrm{McEA}_{0} \\
& +\Delta X_{i} \gamma+\delta+\Delta u_{i j},
\end{aligned}
$$

where $\Delta$ is the difference operator and $\delta=p_{1}-p_{0}$. As shown by Kuminoff and Pope (2014), if we omit $\mathrm{MEA}_{0}$ (resp., $\mathrm{McEA}_{0}$ ) from independent variables, we face conflation bias, i.e., $\beta_{\text {mea } 1}$ (resp., $\left.\beta_{\text {mcea }, 1}\right)$ estimates the mixture of the effect of the event on land prices and the effect of changes in the hedonic curve. Hence, in general, the capitalization effects estimated in the DID analysis are not equal to the marginal willingness to pay. However, $\mathrm{MEA}_{0}$ and $\mathrm{McEA}_{0}$ are conceptually zero for all points in our analysis because no stations are available prior to the event. Hence, we can conclude that the equations to be estimated do not change. 


\subsection{Train types}

After the opening of the entire route, three types of trains run on the Kagoshima route: "Mizuho," "Sakura," and "Tsubame" (Table 13). They differ in terms of number of stations where they stop, travel time, and service frequency. ${ }^{13}$ The fastest train, "Mizuho," stops only at Hakata, Kumamoto and Kagoshima-Chuo stations, which are located in three largest MEAs in Kyushu. The service frequency is around eight times per day along both the in-bound and out-bound lines, and it runs mainly in the morning and the evening. "Sakura" is the second fastest and most frequent service. It stops at about half of the stations and runs once or twice every hour. "Tsubame" is the slowest service and stops at all stations. Some of them only run at the north part of Kagoshima route (i.e., between Kumamoto and Hakata stations), but here we focus on Tsubame, which runs along the entire route.

[Table 13]

It would be possible that the effects of high-speed railways on agglomerations depend on the types of trains that stop in them. In order to address this point, we conduct an additional analysis using the first specification with new two dummies: three types dummy, $T_{3}$, and two types dummy, $T_{2} . T_{3}$ takes one if the point is located in a MEA in which all types of trains stop (i.e., the Fukuoka, Kumamoto, and Kagoshima MEAs). $T_{2}$ takes one if the point is located in a MEA/McEA containing "Mizuho" and all "Sakura" stops. ${ }^{14}$

Interaction terms between these dummies and main independent variables are added to the first specification (1):

$$
\begin{aligned}
\ln \left(p_{i j t}\right) & =\alpha+\beta_{\text {mea }} w_{t} \sum_{l=1}^{L} Z_{j, l}+\beta_{\text {mea }, T 2} w_{t} T_{2} \sum_{l=1}^{L} Z_{j, l}+\beta_{\text {mea }, T 3} w_{t} T_{3} \sum_{l=1}^{L} Z_{j, l} \\
& +\beta_{\text {mcea }} w_{t} \sum_{s=1}^{S} Z_{j, s}+\beta_{\text {mcea }, T 2} w_{t} T_{2} \sum_{s=1}^{S} Z_{j, s} \\
& +X_{i t} \gamma+c_{j}+p_{t}+u_{i j t} .
\end{aligned}
$$

Note here that $\sum_{l=1}^{L} Z_{j, l}$ and $\sum_{s=1}^{S} Z_{j, s}$ are MEA and McEA dummies, respectively. Hence, the estimated values of $\beta_{\text {mea }}, \beta_{\text {mea,T2 }}$, and $\beta_{\text {mea,T3 }}$ (resp. $\beta_{\text {mcea }} \beta_{\text {mcea }, 3}$ and $\beta_{\text {mcea }, 2}$ ) show the effect of the number of train types stopping in MEAs (resp. McEAs) on the MEAs' (resp.

\footnotetext{
${ }^{13}$ Before the whole route's opening, the Kagoshima-route had only "Tsubame", which stops at every station on the route (West Japan Railway Company, 2011).

${ }^{14}$ Some "Sakura" stop at additional stations (see Table 13).
} 
McEAs') land prices. Because no McEA has a station where all three types of trains stop, the above specification does not include an interaction term among three types dummy and McEA dummy.

Table 14 presents the result. Columns (1) and (3) are baseline results that come from columns (4) and (4a) of Table 4. Columns (2) and (4) include the interaction terms with train types dummies. These columns show that the more types of trains that stop in a MEA is, the larger the increases in the MEA's land prices, implying positive effects upon land prices from the number of types of trains that stop. However, an interaction term between two types dummy and McEA dummy does not significantly affect land price. This implies that the existence of a Shinkansen station has no impact on McEAs' land prices, regardless of the number of types of trains stopping in a McEA. ${ }^{15}$

[Table 14]

\section{Concluding Remarks}

The opening and extension of a high-speed railway (Kagoshima route of Kyushu Shinkansen specifically) have connected several urban agglomerations in western Kyushu in Japan and have accelerated integration among them. We aimed to examine their effect on the distribution of economic activities across agglomerations by focusing on changes in land prices. For this purpose, we estimated hedonic price equations and conducted difference-in-difference analyses. Our results showed that the opening and extensions have increased land prices greatly in large metropolitan areas and slightly in their neighboring areas:; thanks to the opening of the entire Kagoshima route, the largest metropolitan area in Kyushu experienced land price increases of around $10.5 \%$, and the second largest metropolitan area saw prices rise by around $7.7 \%$. However, if we extended the estimation by categorizing locations into different groups according to their distance from the nearest Shinkansen station, such positive effects are limited to areas close to Shinkansen stations. In contrast, small metropolitan areas located between large metropolitan areas experienced land price declines, indicating that they became stuck in the agglomeration shadows of the large metropolitan areas. Thus, construction of the high-speed railway has accelerated concentration of economic activities in already-large urban agglomerations in Kyushu, although we found slight propagation of the positive effects to neighboring areas.

\footnotetext{
${ }^{15}$ Note here that some of the trains on the Kagoshima route run only between Hakata and Kumamoto stations. Hence, we also added a dummy representing that a station is located between the two stations. However, the estimated coefficient was not significant.
} 
One important direction of future research would be to disentangle the mechanism behind the differences in impacts of high-speed rail by land-use zoning. Our results showed that residential and commercial zones experienced somewhat different impacts, whereas industry zones experienced non-significant impacts. Although we provided intuitive discussions, fully investigating such a mechanism would require us to build a multi-city model with networks among cities and conduct a structural estimation. This being of course beyond the scope of our current paper would be worth investigating in the future.

\section{References}

P. Krugman, Increasing returns and economic geography, Journal of political economy 99 (1991) $483-499$.

Y. Kanemoto, K. Tokuoka, Proposal for the standards of metropolitan areas of japan, Journal of Applied Regional Science 7 (2002) 1-15. In Japanese.

T. Akamatsu, T. Mori, M. Osawa, Y. Takayama, Spatial Scale of Agglomeration and Dispersion: Theoretical Foundations and Empirical Implications, KIER Working Papers 974, Kyoto University, Institute of Economic Research, 2017.

E. Helpman, The size of regions, in: D. Pines, E. Sadka, I. Zilcha (Eds.), Topics in Public Economics: Theoretical and Applied Analysis, Cambridge University Press, 1998, pp. 33-54.

T. Tabuchi, Urban agglomeration and dispersion: a synthesis of alonso and krugman, Journal of urban economics 44 (1998) 333-351.

S. J. Redding, M. A. Turner, Transportation costs and the spatial organization of economic activity, in: Handbook of regional and urban economics, volume 5, Elsevier, 2015, pp. 13391398.

A. Chandra, E. Thompson, Does public infrastructure affect economic activity?: Evidence from the rural interstate highway system, Regional Science and Urban Economics 30 (2000) $457-490$.

D. Donaldson, Railroads of the raj: Estimating the impact of transportation infrastructure, American Economic Review 108 (2018) 899-934.

D. Donaldson, R. Hornbeck, Railroads and american economic growth: A "market access" approach, The Quarterly Journal of Economics 131 (2016) 799-858. 
A. B. Bernard, A. Moxnes, Y. U. Saito, Production networks, geography and firm performance, Journal of Political Economy (forthcoming).

Ministry of Land, Infrastructure, Transport and Tourism, About the shinkansen railway (shinkansen tetsudo ni tsuite), 2017. URL: http://www.mlit.go.jp/tetudo/tetudo_fr1_000041.html.

S. Rosen, Hedonic prices and implicit markets: product differentiation in pure competition, Journal of political economy 82 (1974) 34-55.

M. Fujita, P. Krugman, A. J. Venables, The spatial economy: Cities, regions, and international trade, MIT press, 2001.

M. Fujita, J.-F. Thisse, Economics of agglomeration: cities, industrial location, and globalization, 2 ed., Cambridge university press, 2013.

Y. Sato, Invitation letter to urban and regional economics (Toshi chiiki keizai-gaku e no shotaijo), Yuhikaku, 2014. In Japanese.

M. J. Melitz, The impact of trade on intra-industry reallocations and aggregate industry productivity, Econometrica 71 (2003) 1695-1725.

N. V. Kuminoff, J. C. Pope, Do "capitalization effects" for public goods reveal the public's willingness to pay?, International Economic Review 55 (2014) 1227-1250.

D. Kawaguchi, N. Yukutake, Estimating the residential land damage of the fukushima nuclear accident, Journal of Urban Economics 99 (2017) 148-160.

West Japan Railway Company, About timetable revision in the spring of 2011 (heisei 23-nen haru daiya kaisei ni tsuite), 2011. URL: https://www . westjr.co.jp/press/article/items/20111216_hiroshima.pdf. 
Figure 1: Kagoshima route and stations of the Kyushu Shinkansen

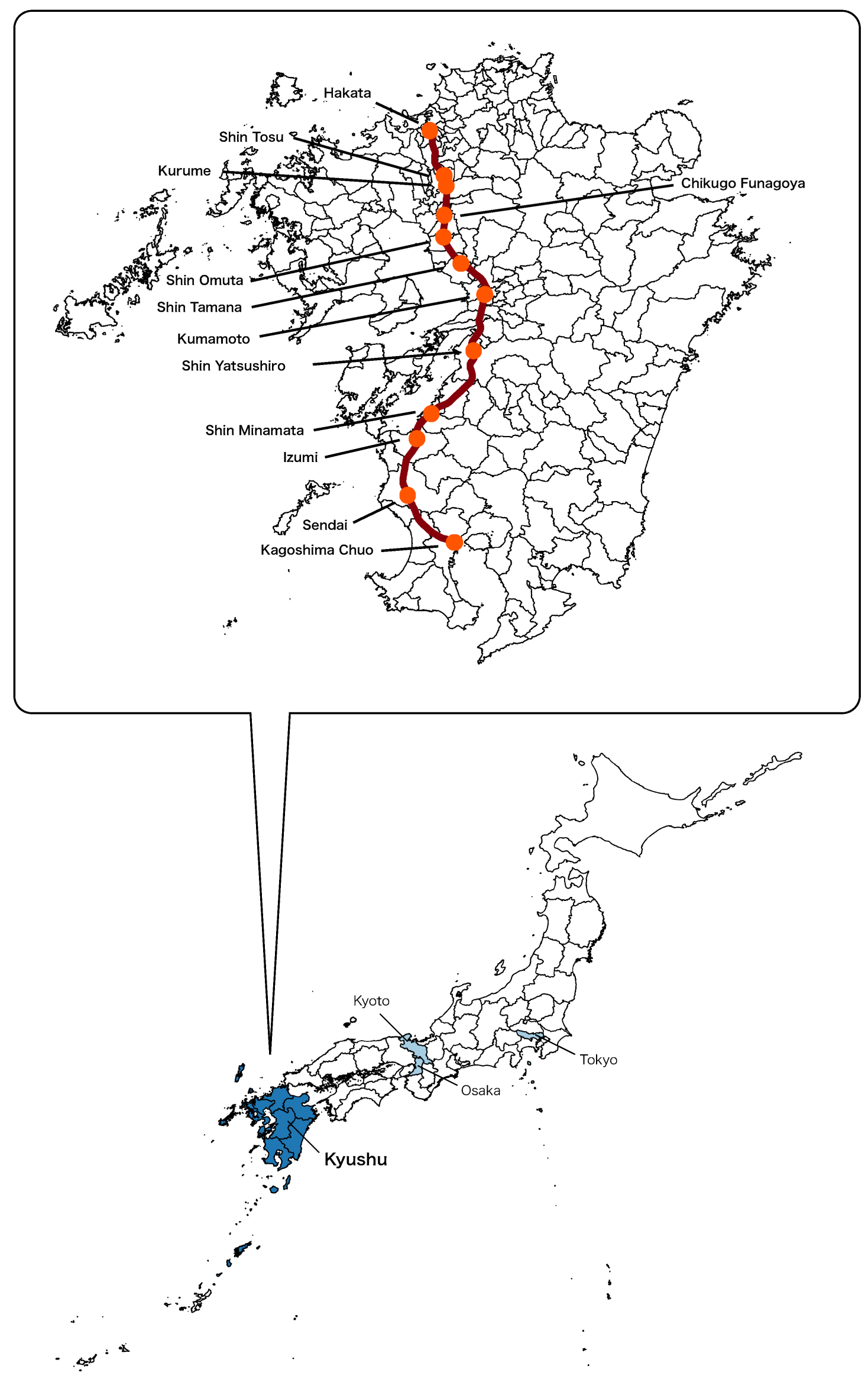


Figure 2: MEAs and the Kagoshima route of the Kyushu Shinkansen

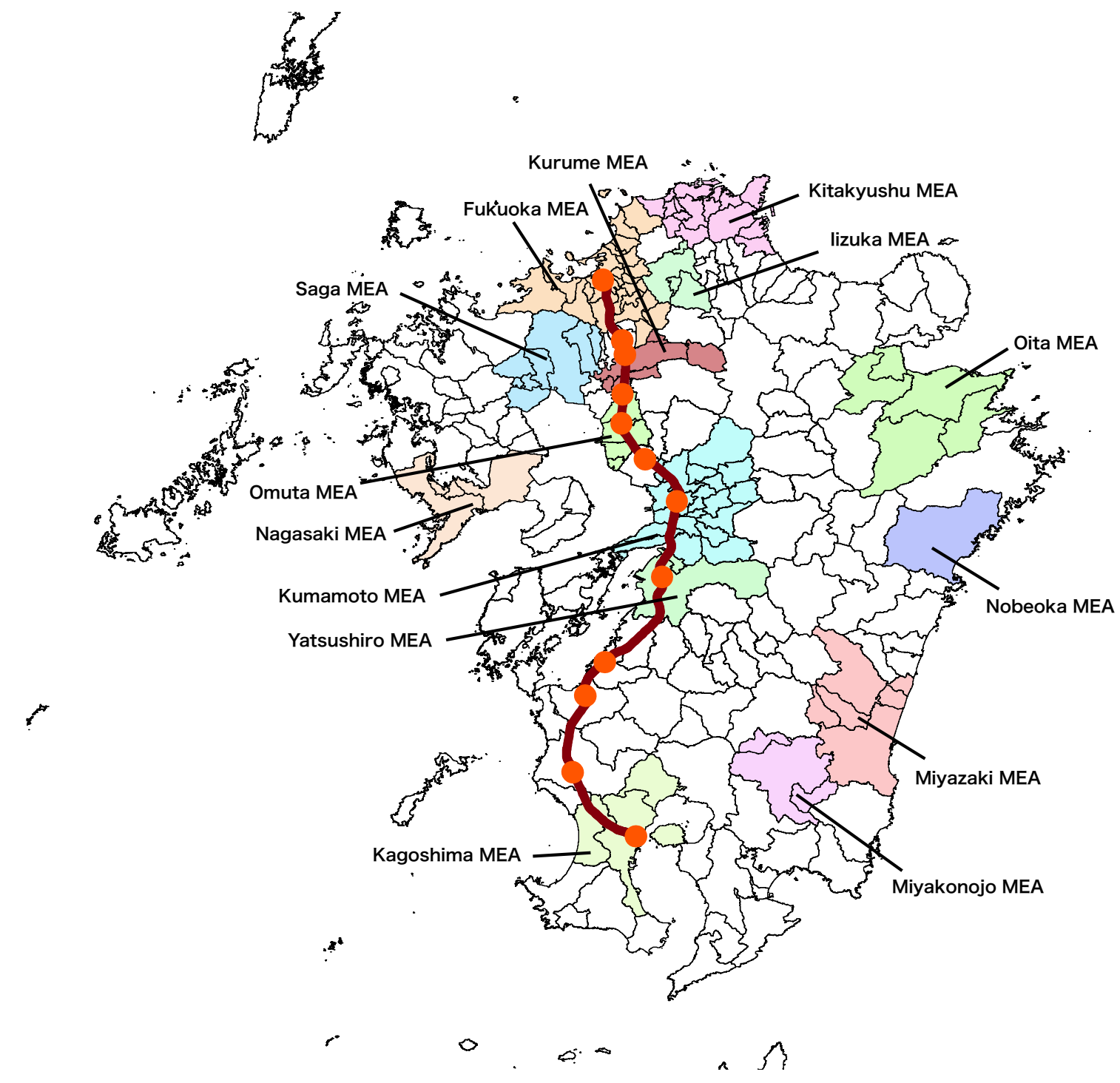


Figure 3: McEAs and the Kagoshima route of the Kyushu Shinkansen

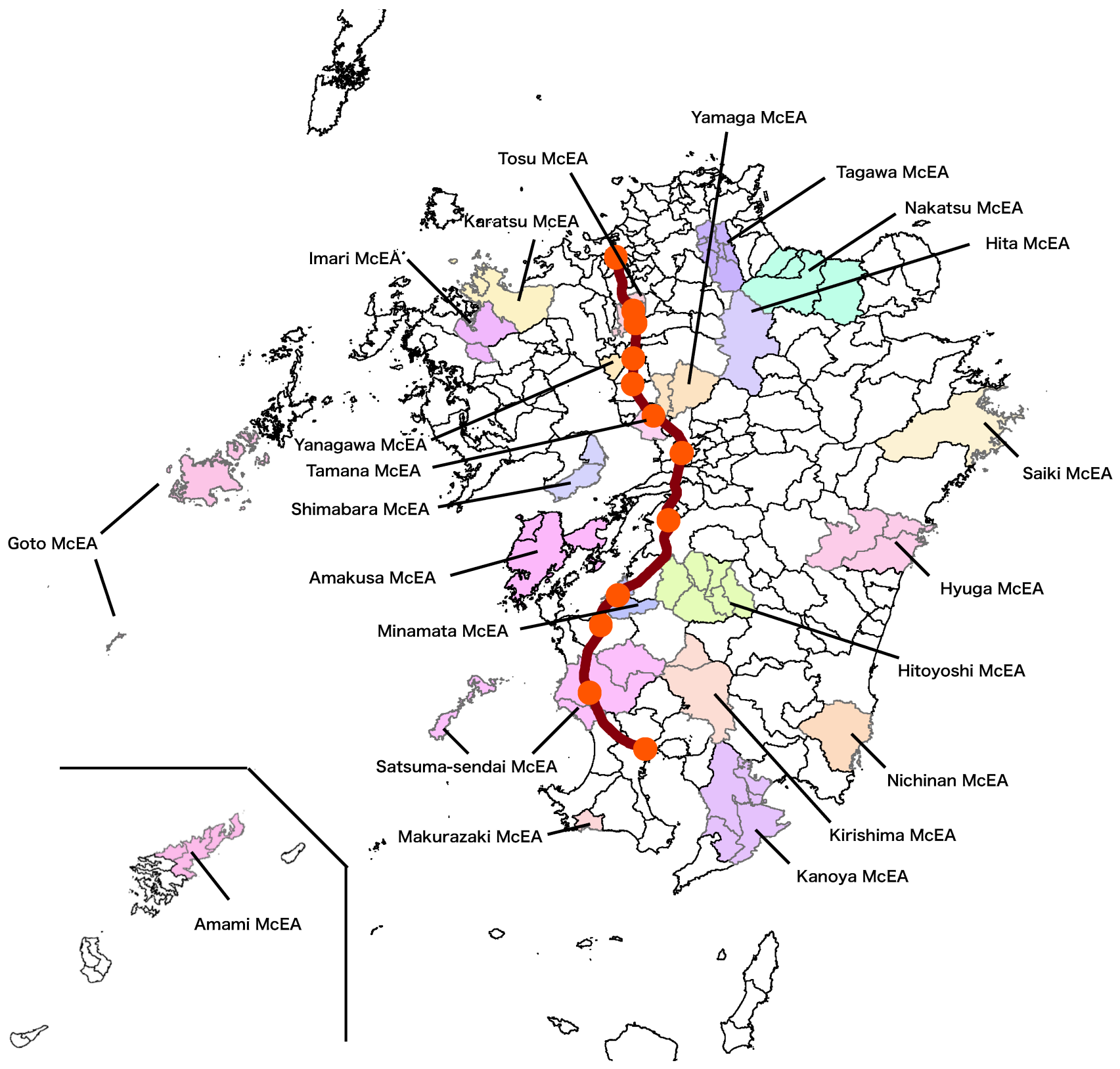


Figure 4: Land price trends

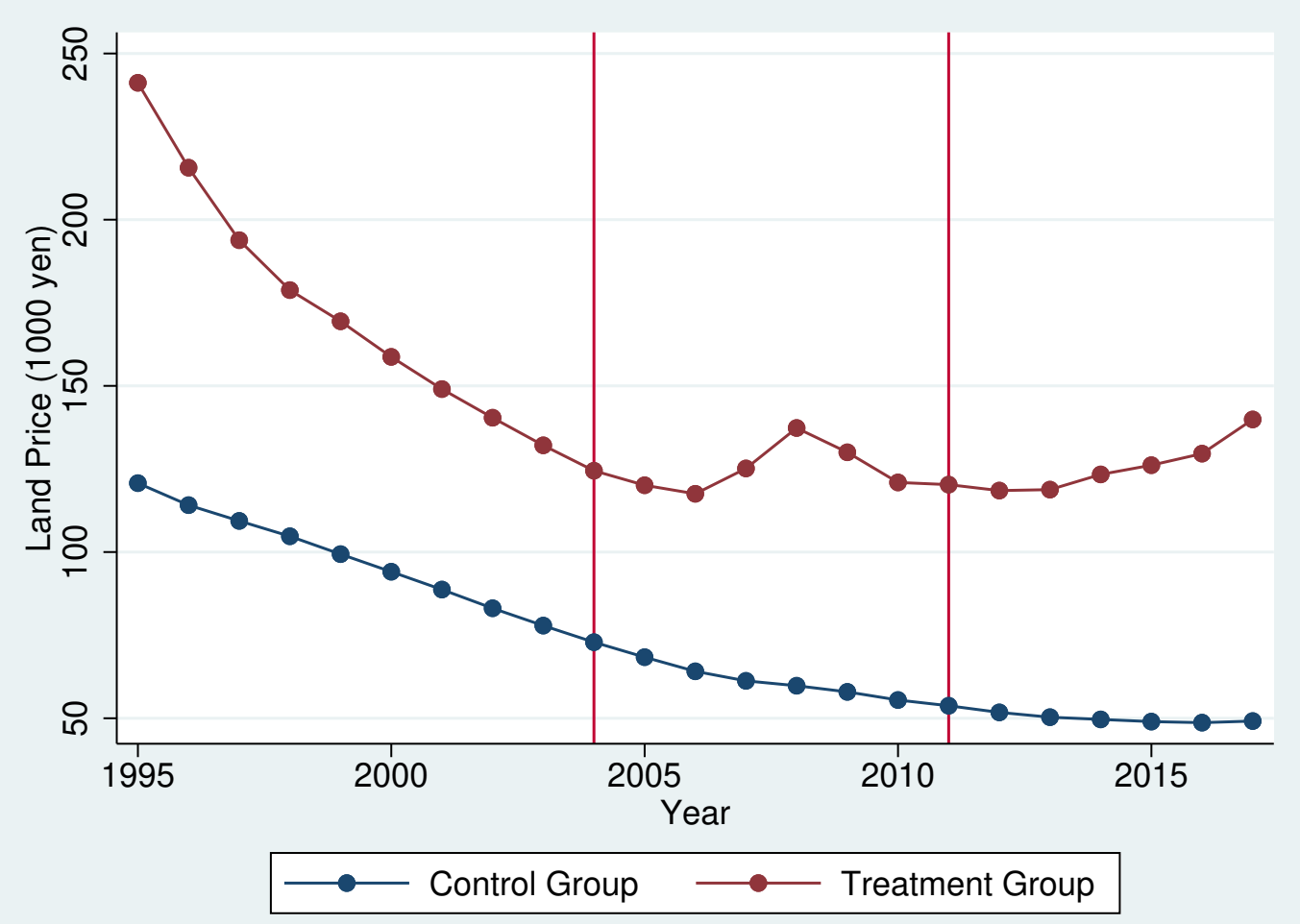


Table 1: Summary descriptive statistics

\begin{tabular}{lllll}
\hline \hline & \multicolumn{2}{l}{ The partial opening } & \multicolumn{2}{c}{ The whole opening } \\
& mean & sd & mean & sd \\
\hline Price & 101,473 & 188,215 & 86,367 & 221,874 \\
MEA dummy & 0.807 & 0.395 & 0.802 & 0.399 \\
McEA dummy & 0.109 & 0.311 & 0.119 & 0.323 \\
Distance from station (m) & 2,882 & 4,658 & 2,804 & 4,683 \\
Building-area ratio & 44.65 & 28.62 & 62.92 & 11.49 \\
Floor-area ratio & 225.6 & 118.2 & 219.6 & 113.9 \\
Acreage & 500.7 & 1,609 & 542.9 & 2,904 \\
Land use regulation dummies & & & & \\
$\quad$ no regulation & 0.129 & 0.335 & 0.133 & 0.340 \\
$\quad$ commercial purpose & 0.206 & 0.404 & 0.215 & 0.411 \\
$\quad$ industrial purpose & 0.0612 & 0.240 & 0.0593 & 0.236 \\
$\quad$ residential purpose & 0.604 & 0.489 & 0.592 & 0.491 \\
Supply system dummies & & & & \\
$\quad$ water & 0.986 & 0.119 & 0.990 & 0.0980 \\
$\quad$ gas & 0.486 & 0.500 & 0.497 & 0.500 \\
$\quad$ drain & 0.657 & 0.475 & 0.743 & 0.437 \\
\hline Sample size & 5488 & & 4740 & \\
\hline \hline
\end{tabular}

Table 2: Characteristics of MEAs in Kyushu

\begin{tabular}{|c|c|c|c|c|c|c|c|c|}
\hline MEA & $\begin{array}{l}\text { Partial } \\
\text { Opening }\end{array}$ & $\begin{array}{l}\text { Entire } \\
\text { Opening }\end{array}$ & $\begin{array}{l}\text { Population } \\
\text { (1 thousands) }\end{array}$ & $\begin{array}{l}\text { Total area } \\
\text { (ha) }\end{array}$ & $\begin{array}{l}\text { Inhabitable } \\
\text { land (ha) }\end{array}$ & $\begin{array}{l}\text { Taxable } \\
\text { Income } \\
\text { (1 billion) }\end{array}$ & $\begin{array}{l}\text { Number of } \\
\text { establishments }\end{array}$ & $\begin{array}{l}\text { Number of } \\
\text { employees }\end{array}$ \\
\hline Kitakyushu MEA & & & 1440.6 & 129122 & 72824 & 1669.1 & 66995 & 683276 \\
\hline Fukuoka MEA & & 夫 & 2495.6 & 128261 & 76431 & 3281.3 & 109819 & 1260171 \\
\hline Omuta MEA & & * & 246.8 & 33222 & 25044 & 227.6 & 11120 & 97995 \\
\hline Kurume MEA & & $\star$ & 432.4 & 46841 & 35915 & 479.4 & 20422 & 192200 \\
\hline Iizuka MEA & & & 196.5 & 38356 & 19273 & 188.1 & 8895 & 81356 \\
\hline Saga MEA & & & 405.1 & 94134 & 59537 & 447.9 & 19578 & 191323 \\
\hline Nagasaki MEA & & & 944.6 & 150624 & 76446 & 1035.4 & 42900 & 429339 \\
\hline Sasebo MEA & & & 304.6 & 55199 & 25237 & 315.2 & 14740 & 134210 \\
\hline Kumamoto MEA & & 夫 & 1102.4 & 160364 & 97206 & 1226.8 & 47198 & 505462 \\
\hline Yatsushiro MEA & $\star$ & $\star$ & 145.0 & 71389 & 20918 & 129.4 & 7293 & 59197 \\
\hline Oita MEA & & & 743.3 & 191335 & 65197 & 848.7 & 34027 & 352656 \\
\hline Miyazaki MEA & & & 506.3 & 156073 & 57419 & 544.5 & 24572 & 234910 \\
\hline Miyakonojo MEA & & & 243.6 & 123909 & 52532 & 209.5 & 12010 & 106413 \\
\hline Nobeoka MEA & & & 131.2 & 86800 & 13669 & 123.1 & 6933 & 59020 \\
\hline Kagoshima MEA & 夫 & 夫 & 731.5 & 103144 & 43381 & 826.2 & 35205 & 348729 \\
\hline
\end{tabular}

The data sources for each column are as follows. Population data are from Population Census, Population Estimates (MIC). Total area data are from Population Census, Statistical reports on the land area by prefectures and municipalities in Japan (MIC and MLIT). Inhabitable land data are from statistical reports on the land area by prefectures and municipalities in Japan (MLIT). Taxable income data are from survey about municipal tax "Shichoson zei kazei jokyo-to no Shirabe (in Japanese)" (MIC). Data on number of establishments and number of employees are from 2009 Economic census for business frame (MIC). "MIC" represents Ministry of Internal Affairs and Communications, and "MLIT" represents Ministry of Land, Infrastructure, Transport and Tourism. 
Table 3: Characteristics of McEAs in Kyushu

\begin{tabular}{|c|c|c|c|c|c|c|c|c|}
\hline McEA & $\begin{array}{l}\text { Partial } \\
\text { Opening }\end{array}$ & $\begin{array}{l}\text { Entire } \\
\text { Opening }\end{array}$ & $\begin{array}{l}\text { Population } \\
\text { (1 thousands) }\end{array}$ & $\begin{array}{l}\text { Total area } \\
\text { (ha) }\end{array}$ & $\begin{array}{l}\text { Inhabitable } \\
\text { land (ha) }\end{array}$ & $\begin{array}{l}\text { Taxable } \\
\text { Income } \\
\text { (1 billion) }\end{array}$ & $\begin{array}{l}\text { Number of } \\
\text { establishments }\end{array}$ & $\begin{array}{l}\text { Number of } \\
\text { employees }\end{array}$ \\
\hline Tagawa McEA & & & 134.5 & 36365 & 14549 & 106.3 & 5920 & 46250 \\
\hline Yanagawa McEA & & & 71.4 & 7688 & 7675 & 65.7 & 3364 & 25689 \\
\hline Karatsu McEA & & & 133.3 & 52349 & 25624 & 125.7 & 6678 & 56560 \\
\hline Tosu McEA & & 夫 & 113.1 & 14574 & 10414 & 132.6 & 4727 & 58104 \\
\hline Imari McEA & & & 78.1 & 32082 & 14747 & 73.3 & 4423 & 37911 \\
\hline Shimabara McEA & & & 97.8 & 25269 & 15292 & 76.4 & 5878 & 38523 \\
\hline Goto McEA & & & 40.6 & 42085 & 14687 & 32.7 & 2741 & 15636 \\
\hline Hitoyoshi McEA & & & 120.7 & 160897 & 35107 & 95.2 & 6317 & 48502 \\
\hline Minamata McEA & $\star$ & 夫 & 32.0 & 19688 & 5321 & 27.4 & 1678 & 14062 \\
\hline Tamana McEA & & $\star$ & 69.5 & 15255 & 12559 & 65.8 & 2863 & 24236 \\
\hline Yamaga McEA & & & 66.6 & 39842 & 19169 & 55.1 & 3012 & 25679 \\
\hline Amakusa McEA & & & 97.4 & 75034 & 24338 & 77.0 & 6203 & 39674 \\
\hline Nakatsu McEA & & & 208.9 & 131619 & 44702 & 205.4 & 10642 & 92978 \\
\hline Hita McEA & & & 70.9 & 66619 & 11244 & 64.2 & 4724 & 33007 \\
\hline Saiki McEA & & & 77.0 & 90352 & 11668 & 70.7 & 4537 & 32979 \\
\hline Nichinan McEA & & & 57.7 & 53612 & 11632 & 52.1 & 3227 & 24076 \\
\hline Hyuga McEA & & & 88.3 & 90549 & 12792 & 77.9 & 4989 & 38200 \\
\hline Kanoya McEA & & & 152.2 & 104814 & 40024 & 127.7 & 7644 & 62926 \\
\hline Makurazaki McEA & & & 23.6 & 7488 & 4309 & 21.4 & 1393 & 10570 \\
\hline Satsumasendai McEA & 夫 & $\star$ & 154.8 & 109897 & 37266 & 139.2 & 7765 & 69155 \\
\hline Kirishima McEA & & & 139.1 & 74801 & 23545 & 129.6 & 5802 & 62991 \\
\hline Amami McEA & & & 54.0 & 47838 & 8560 & 44.2 & 3451 & 22928 \\
\hline
\end{tabular}

The data sources for each column are as follows. Population data are from Population Census, Population Estimates (MIC). Total area data are from Population Census, Statistical reports on the land area by prefectures and municipalities in Japan (MIC and MLIT). Inhabitable land data are from statistical reports on the land area by prefectures and municipalities in Japan (MLIT). Taxable income data are from survey about municipal tax "Shichoson zei kazei jokyo-to no Shirabe (in Japanese)" (MIC). Data on number of establishments and number of employees are from 2009 Economic census for business frame (MIC). "MIC" represents Ministry of Internal Affairs and Communications, and "MLIT" represents Ministry of Land, Infrastructure, Transport and Tourism. 
Table 4: Analysis 1

\begin{tabular}{|c|c|c|c|c|c|c|c|c|c|c|}
\hline & \multicolumn{4}{|c|}{ Opening } & \multicolumn{4}{|c|}{ Extension } & \multicolumn{2}{|c|}{ Extension } \\
\hline & $(1)$ & $(2)$ & $(3)$ & $(3 a)$ & $(4)$ & $(5)$ & $(6)$ & (6a) & $(7)$ & $(7 a)$ \\
\hline \multirow[t]{2}{*}{ MEA $\times$ After } & $-0.094^{* * *}$ & & $-0.109^{* * *}$ & & $0.086^{* * *}$ & & $0.096^{* * *}$ & & $0.089^{* * *}$ & \\
\hline & $(0.027)$ & & $(0.033)$ & & $(0.020)$ & & $(0.028)$ & & $(0.027)$ & \\
\hline \multirow[t]{2}{*}{ McEA $\times$ After } & & $0.076^{* *}$ & -0.024 & & & $-0.071^{* * *}$ & 0.017 & & 0.018 & \\
\hline & & $(0.032)$ & $(0.036)$ & & & $(0.023)$ & $(0.030)$ & & $(0.028)$ & \\
\hline \multirow[t]{2}{*}{ MEA w/ the stations $\times$ After } & & & & $0.113^{* * *}$ & & & & $0.078^{* * *}$ & & $0.076^{* * *}$ \\
\hline & & & & $(0.028)$ & & & & $(0.023)$ & & $(0.023)$ \\
\hline \multirow[t]{2}{*}{ McEA w/ the stations $\times$ After } & & & & 0.031 & & & & -0.006 & & -0.002 \\
\hline & & & & $(0.027)$ & & & & $(0.023)$ & & $(0.024)$ \\
\hline Covariates & $\mathrm{Y}$ & Y & $\mathrm{Y}$ & Y & $\mathrm{Y}$ & $\mathrm{Y}$ & $\mathrm{Y}$ & Y & $\mathrm{Y}$ & $\mathrm{Y}$ \\
\hline Time F.E. & $\mathrm{Y}$ & $\mathrm{Y}$ & $\mathrm{Y}$ & $\mathrm{Y}$ & $\mathrm{Y}$ & $\mathrm{Y}$ & $\mathrm{Y}$ & $\mathrm{Y}$ & $\mathrm{Y}$ & $\mathrm{Y}$ \\
\hline Municipalities F.E. & $\mathrm{Y}$ & $\mathrm{Y}$ & $\mathrm{Y}$ & $\mathrm{Y}$ & $\mathrm{Y}$ & $\mathrm{Y}$ & $\mathrm{Y}$ & $\mathrm{Y}$ & $\mathrm{Y}$ & $\mathrm{Y}$ \\
\hline$N$ & 5488 & 5488 & 5488 & 5488 & 4740 & 4740 & 4740 & 4740 & 4678 & 4678 \\
\hline$R^{2}$ & 0.815 & 0.815 & 0.815 & 0.815 & 0.830 & 0.830 & 0.830 & 0.830 & 0.832 & 0.832 \\
\hline
\end{tabular}

Standard errors in parentheses are clustered in the municipalities. Columns (1)-(3a) are the results for the opening in 2004 . They use data for 2001 and 2007. Columns (4)-(7a) are the results for the extension in 2011. Columns (4)-(6a) use data for 2008 and 2014. Columns (7) and (7a) use 2009 data instead of 2008 data in order to mitigate the effects of the Great Recession on land prices. ${ }^{*} p<0.1,{ }^{* *} p<0.05,{ }^{* * *} p<0.01$ 
Table 5: Analysis 2

\begin{tabular}{|c|c|c|c|c|c|c|c|}
\hline & \multicolumn{3}{|c|}{ Opening } & \multicolumn{3}{|c|}{ Extension } & \multirow{2}{*}{$\begin{array}{c}\text { Extension } \\
(7)\end{array}$} \\
\hline & (1) & $(2)$ & $(3)$ & $(4)$ & $(5)$ & (6) & \\
\hline \multirow[t]{2}{*}{ Fukuoka MEA $\times$ After } & & & & $0.105^{* * *}$ & & $0.105^{* * *}$ & $0.104^{* * *}$ \\
\hline & & & & $(0.024)$ & & $(0.024)$ & $(0.024)$ \\
\hline \multirow[t]{2}{*}{ Kurume MEA $\times$ After } & & & & $0.056^{* *}$ & & $0.056^{* *}$ & $0.058^{* * *}$ \\
\hline & & & & $(0.023)$ & & $(0.023)$ & $(0.022)$ \\
\hline \multirow[t]{2}{*}{ Omuta MEA $\times$ After } & & & & -0.053 & & -0.053 & -0.032 \\
\hline & & & & $(0.036)$ & & $(0.036)$ & $(0.028)$ \\
\hline \multirow[t]{2}{*}{ Kumamoto MEA $\times$ After } & & & & $0.077^{* * *}$ & & $0.077^{* * *}$ & $0.073^{* * *}$ \\
\hline & & & & $(0.021)$ & & $(0.022)$ & $(0.018)$ \\
\hline \multirow[t]{2}{*}{ Yatsushiro MEA $\times$ After } & $-0.081^{* * *}$ & & $-0.080^{* * *}$ & $-0.066^{* * *}$ & & $-0.066^{* * *}$ & $-0.091^{* * *}$ \\
\hline & $(0.017)$ & & $(0.018)$ & $(0.024)$ & & $(0.024)$ & $(0.027)$ \\
\hline \multirow[t]{2}{*}{ Kagoshima MEA $\times$ After } & $0.132^{* * *}$ & & $0.132^{* * *}$ & $0.070^{* * *}$ & & $0.070^{* * *}$ & $0.051^{* *}$ \\
\hline & $(0.015)$ & & $(0.015)$ & $(0.026)$ & & $(0.026)$ & $(0.021)$ \\
\hline \multirow[t]{2}{*}{ Tosu McEA $\times$ After } & & & & & -0.013 & 0.018 & 0.022 \\
\hline & & & & & $(0.030)$ & $(0.028)$ & $(0.030)$ \\
\hline \multirow[t]{2}{*}{ Tamana McEA $\times$ After } & & & & & -0.034 & -0.003 & 0.005 \\
\hline & & & & & $(0.022)$ & $(0.016)$ & $(0.014)$ \\
\hline \multirow[t]{2}{*}{ Minamata McEA $\times$ After } & & $-0.062^{* * *}$ & $-0.055^{* * *}$ & & $-0.068^{* * *}$ & $-0.037^{* * *}$ & -0.009 \\
\hline & & $(0.019)$ & $(0.018)$ & & $(0.014)$ & $(0.012)$ & $(0.010)$ \\
\hline \multirow[t]{2}{*}{ Satsumasendai McEA $\times$ After } & & 0.041 & $0.048^{*}$ & & $-0.060^{* *}$ & -0.029 & -0.033 \\
\hline & & $(0.027)$ & $(0.027)$ & & $(0.024)$ & $(0.024)$ & $(0.021)$ \\
\hline Covariates & $\mathrm{Y}$ & $\mathrm{Y}$ & $\mathrm{Y}$ & $\mathrm{Y}$ & $\mathrm{Y}$ & $\mathrm{Y}$ & $\mathrm{Y}$ \\
\hline Time F.E. & $\mathrm{Y}$ & $\mathrm{Y}$ & $\mathrm{Y}$ & $\mathrm{Y}$ & $\mathrm{Y}$ & $\mathrm{Y}$ & $\mathrm{Y}$ \\
\hline Municipalities F.E. & $\mathrm{Y}$ & $\mathrm{Y}$ & $\mathrm{Y}$ & $\mathrm{Y}$ & Y & $\mathrm{Y}$ & $\mathrm{Y}$ \\
\hline$N$ & 5488 & 5488 & 5488 & 4740 & 4740 & 4740 & 4678 \\
\hline$R^{2}$ & 0.815 & 0.815 & 0.815 & 0.830 & 0.830 & 0.830 & 0.833 \\
\hline
\end{tabular}

Standard errors in parentheses are clustered in the municipalities. Columns (1)-(3) are the results for the opening in 2004 . They use data for 2001 and 2007. Columns (4)-(7) are the results for the extension in 2011. Columns (4)-(6) use data for 2008 and 2014. Columns (7) uses 2009 data instead of 2008 data in order to mitigate the effects of the Great Recession on land prices. ${ }^{*} p<0.1,{ }^{* *} p<0.05,{ }^{* * *} p<0.01$ 
Table 6: Analysis 3 (opening in 2004)

\begin{tabular}{|c|c|c|c|c|c|c|c|c|}
\hline NAME & $\mathrm{MEA} / \mathrm{McEA}$ & Station & $0-5 \mathrm{~km}$ & $5-10 \mathrm{~km}$ & $10-15 \mathrm{~km}$ & $15-20 \mathrm{~km}$ & $20-25 \mathrm{~km}$ & $25 \mathrm{~km}-$ \\
\hline \multicolumn{2}{|c|}{ Avg. of MEAs and McEAs } & & $-0.093^{* * *}$ & $0.209^{* * *}$ & $0.463^{* * *}$ & -0.030 & $-0.088^{*}$ & \\
\hline Kitakyushu & MEA & & & & & & & $-0.137^{* * *}$ \\
\hline Fukuoka & MEA & & & & & & & $-0.162^{* * *}$ \\
\hline Omuta & MEA & & & & & & & -0.057 \\
\hline Kurume & MEA & & & & & & & $-0.162^{* * *}$ \\
\hline Iizuka & MEA & & & & & & & 0.063 \\
\hline Saga & MEA & & & & & & & 0.007 \\
\hline Nagasaki & MEA & & & & & & & $-0.235^{* * *}$ \\
\hline Sasebo & MEA & & & & & & & $-0.088^{* *}$ \\
\hline Kumamoto & MEA & & & & $-0.404^{* * *}$ & -0.076 & -0.179 & $-0.225^{* * *}$ \\
\hline Yatsushiro & MEA & $\star$ & $-0.096^{* * *}$ & $-0.457^{* * *}$ & $-0.461^{* * *}$ & & & \\
\hline Oita & MEA & & & & & & & $-0.099 * * *$ \\
\hline Miyazaki & MEA & & & & & & & $0.058^{* *}$ \\
\hline Miyakonojo & MEA & & & & & & & 0.004 \\
\hline Nobeoka & MEA & & & & & & & $0.095^{* * *}$ \\
\hline Kagoshima & MEA & $\star$ & $0.264^{* * *}$ & $-0.323^{* * *}$ & $-0.695^{* * *}$ & 0.130 & $-0.174^{* *}$ & $-0.861^{* * *}$ \\
\hline Tagawa & McEA & & & & & & & -0.035 \\
\hline Yanagawa & McEA & & & & & & & $-0.135^{* * *}$ \\
\hline Karatsu & McEA & & & & & & & $0.063^{*}$ \\
\hline Tosu & McEA & & & & & & & -0.045 \\
\hline Imari & McEA & & & & & & & 0.101 \\
\hline Shimabara & McEA & & & & & & & $0.151^{* *}$ \\
\hline Goto & McEA & & & & & & & $-0.410^{* * *}$ \\
\hline Hitoyoshi & McEA & & & & & & & $-0.116^{* * *}$ \\
\hline Minamata & McEA & $\star$ & $-0.065^{* * *}$ & & & & & \\
\hline Tamana & McEA & & & & & & & $-0.134^{* * *}$ \\
\hline Yamaga & McEA & & & & & & & $0.318^{* * *}$ \\
\hline Amakusa & McEA & & & & & & & $-0.309^{* * *}$ \\
\hline Nakatsu & McEA & & & & & & & $-0.071^{*}$ \\
\hline Hita & McEA & & & & & & & $-0.132^{* * *}$ \\
\hline Saiki & McEA & & & & & & & $-0.132^{* * *}$ \\
\hline Nichinan & McEA & & & & & & & $0.066^{*}$ \\
\hline Hyuga & McEA & & & & & & & $0.138^{* * *}$ \\
\hline Kanoya & McEA & & & & & & & $-0.087^{* *}$ \\
\hline Makurazaki & McEA & & & & & & & -0.013 \\
\hline Satsumasendai & McEA & $\star$ & $0.070^{* *}$ & -0.112 & $-0.603^{* * *}$ & 0.038 & & \\
\hline Kirishima & McEA & & & & & & & $-0.087^{*}$ \\
\hline Amami & McEA & & & & & & & 0.012 \\
\hline
\end{tabular}

Standard errors are clustered in the municipalities. This shows the results for the opening in 2004 . It uses data for 2001 and 2007 . ${ }^{*} p<0.1,{ }^{*}$

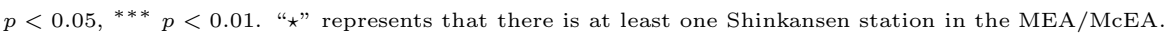


Table 7: Analysis 3 (extension in 2011)

\begin{tabular}{|c|c|c|c|c|c|c|c|c|}
\hline NAME & $\mathrm{MEA} / \mathrm{McEA}$ & Station & $0-5 \mathrm{~km}$ & $5-10 \mathrm{~km}$ & $10-15 \mathrm{~km}$ & $15-20 \mathrm{~km}$ & $20-25 \mathrm{~km}$ & $25 \mathrm{~km}-$ \\
\hline \multicolumn{2}{|c|}{ Avg. of MEAs and McEAs } & & $-0.056^{* * *}$ & $0.281^{* * *}$ & -0.098 & -0.013 & 0.037 & \\
\hline Kitakyushu & MEA & & & & & & & $0.095^{* * *}$ \\
\hline Fukuoka & MEA & $\star$ & $0.424^{* * *}$ & -0.125 & 0.040 & 0.093 & -0.084 & -0.005 \\
\hline Omuta & MEA & $\star$ & $0.184^{* * *}$ & $-0.357^{* *}$ & -0.032 & & & \\
\hline Kurume & MEA & * & $0.186^{* * *}$ & $-0.226^{* *}$ & $0.272^{* *}$ & $0.425^{* *}$ & & \\
\hline Iizuka & MEA & & & & & & 0.005 & 0.011 \\
\hline Saga & MEA & & & $-0.214^{* *}$ & -0.077 & 0.018 & -0.020 & -0.006 \\
\hline Nagasaki & MEA & & & & & & & $0.095^{* * *}$ \\
\hline Sasebo & MEA & & & & & & & $0.047^{* *}$ \\
\hline Kumamoto & MEA & $\star$ & $0.275^{* * *}$ & -0.115 & 0.082 & $-0.206^{* *}$ & 0.006 & \\
\hline Yatsushiro & MEA & $\star$ & $0.080^{* * *}$ & $-0.541^{* * *}$ & $0.258^{* *}$ & & & \\
\hline Oita & MEA & & & & & & & $0.073^{* * *}$ \\
\hline Miyazaki & MEA & & & & & & & 0.069 \\
\hline Miyakonojo & MEA & & & & & & & 0.033 \\
\hline Nobeoka & MEA & & & & & & & $0.136^{* * *}$ \\
\hline Kagoshima & MEA & $\star$ & $0.415^{* * *}$ & $-0.308^{* * *}$ & -0.215 & 0.065 & $-0.501^{* * *}$ & $-1.259^{* * *}$ \\
\hline Tagawa & McEA & & & & & & & $0.094^{* * *}$ \\
\hline Yanagawa & McEA & & & $-0.222^{* *}$ & & & & \\
\hline Karatsu & McEA & & & & & & & -0.012 \\
\hline Tosu & McEA & $\star$ & $0.167^{* * *}$ & $-0.383^{* * *}$ & & & & \\
\hline Imari & McEA & & & & & & & $0.063^{* * *}$ \\
\hline Shimabara & McEA & & & & & & & 0.004 \\
\hline Goto & McEA & & & & & & & $-0.123^{* * *}$ \\
\hline Hitoyoshi & McEA & & & & & & & $-0.134 * * *$ \\
\hline Minamata & McEA & $\star$ & $0.075^{* * *}$ & & & & & \\
\hline Tamana & McEA & $\star$ & $0.225^{* * *}$ & $-0.455^{* * *}$ & & & & \\
\hline Yamaga & McEA & & & & -0.041 & & & \\
\hline Amakusa & McEA & & & & & & & $-0.114^{* * *}$ \\
\hline Nakatsu & McEA & & & & & & & 0.059 \\
\hline Hita & McEA & & & & & & & $0.040^{*}$ \\
\hline Saiki & McEA & & & & & & & -0.010 \\
\hline Nichinan & McEA & & & & & & & 0.017 \\
\hline Hyuga & McEA & & & & & & & $0.163^{* * *}$ \\
\hline Kanoya & McEA & & & & & & & $-0.147^{* * *}$ \\
\hline Makurazaki & McEA & & & & & & & $-0.162^{* * *}$ \\
\hline Satsumasendai & McEA & $\star$ & $0.241^{* * *}$ & -0.189 & -0.023 & 0.059 & & \\
\hline Kirishima & McEA & & & & & & & 0.045 \\
\hline Amami & McEA & & & & & & & $0.089^{* *}$ \\
\hline
\end{tabular}

Standard errors are clustered in the municipalities. This shows the results for the extension in 2011 . It uses data for 2008 and 2014 . $*<<0.1$, ** $p<0.05,{ }^{* * *} p<0.01$. “*” represents that there is at least one Shinkansen station in the MEA/McEA. 
Table 8: Analysis3 (extension in 2011, 2009-2014)

\begin{tabular}{|c|c|c|c|c|c|c|c|c|}
\hline NAME & $\mathrm{MEA} / \mathrm{McEA}$ & Station & $0-5 \mathrm{~km}$ & $5-10 \mathrm{~km}$ & $10-15 \mathrm{~km}$ & $15-20 \mathrm{~km}$ & $20-25 \mathrm{~km}$ & $25 \mathrm{~km}-$ \\
\hline \multicolumn{2}{|c|}{ Avg. of MEAs and McEAs } & & $-0.053^{* * *}$ & $0.276^{* *}$ & -0.088 & -0.011 & 0.055 & \\
\hline Kitakyushu & MEA & & & & & & & $0.091^{* * *}$ \\
\hline Fukuoka & MEA & $\star$ & $0.420^{* * *}$ & -0.132 & 0.021 & 0.108 & -0.056 & 0.005 \\
\hline Omuta & MEA & $\star$ & $0.205^{* * *}$ & $-0.332^{* *}$ & -0.044 & & & \\
\hline Kurume & MEA & $\star$ & $0.182^{* * *}$ & $-0.224^{* *}$ & $0.255^{* *}$ & $0.440^{* *}$ & & \\
\hline Iizuka & MEA & & & & & & 0.025 & 0.032 \\
\hline Saga & MEA & & & $-0.230^{* *}$ & -0.101 & 0.004 & -0.052 & -0.022 \\
\hline Nagasaki & MEA & & & & & & & $0.075^{* * *}$ \\
\hline Sasebo & MEA & & & & & & & $0.059^{* * *}$ \\
\hline Kumamoto & MEA & $\star$ & $0.262^{* * *}$ & -0.122 & 0.066 & $-0.201^{* *}$ & 0.005 & \\
\hline Yatsushiro & MEA & $\star$ & $0.051^{* * *}$ & $-0.572^{* * *}$ & $0.213^{* *}$ & & & \\
\hline Oita & MEA & & & & & & & $0.075^{* * *}$ \\
\hline Miyazaki & MEA & & & & & & & 0.046 \\
\hline Miyakonojo & MEA & & & & & & & 0.033 \\
\hline Nobeoka & MEA & & & & & & & $0.114^{* * *}$ \\
\hline Kagoshima & MEA & $\star$ & $0.387^{* * *}$ & $-0.332^{* * *}$ & -0.249 & 0.063 & $-0.523^{* * *}$ & $-1.286^{* * *}$ \\
\hline Tagawa & McEA & & & & & & & $0.081^{* * *}$ \\
\hline Yanagawa & McEA & & & $-0.212^{* *}$ & & & & \\
\hline Karatsu & McEA & & & & & & & -0.022 \\
\hline Tosu & McEA & $\star$ & $0.165^{* * *}$ & $-0.384^{* * *}$ & & & & \\
\hline Imari & McEA & & & & & & & $0.068^{* * *}$ \\
\hline Shimabara & McEA & & & & & & & 0.019 \\
\hline Goto & McEA & & & & & & & $-0.070^{* * *}$ \\
\hline Hitoyoshi & McEA & & & & & & & $-0.095 * * *$ \\
\hline Minamata & McEA & $\star$ & $0.096^{* * *}$ & & & & & \\
\hline Tamana & McEA & $\star$ & $0.228^{* * *}$ & $-0.449^{* * *}$ & & & & \\
\hline Yamaga & McEA & & & & -0.066 & & & \\
\hline Amakusa & McEA & & & & & & & $-0.047^{* *}$ \\
\hline Nakatsu & McEA & & & & & & & 0.060 \\
\hline Hita & McEA & & & & & & & 0.026 \\
\hline Saiki & McEA & & & & & & & 0.020 \\
\hline Nichinan & McEA & & & & & & & 0.015 \\
\hline Hyuga & McEA & & & & & & & $0.145^{* * *}$ \\
\hline Kanoya & $\mathrm{McEA}$ & & & & & & & $-0.126^{* *}$ \\
\hline Makurazaki & McEA & & & & & & & $-0.124^{* * *}$ \\
\hline Satsumasendai & McEA & $\star$ & $0.225^{* * *}$ & -0.186 & -0.038 & 0.047 & & \\
\hline Kirishima & McEA & & & & & & & 0.041 \\
\hline Amami & McEA & & & & & & & $0.077^{* *}$ \\
\hline
\end{tabular}

Standard errors are clustered in the municipalities. This shows the results for the extension in 2011 . It uses data for 2009 and 2014 . $*<<0.1$, ** $p<0.05,{ }^{* * *} p<0.01$. "*” represents that there is at least one Shinkansen station in the MEA/McEA. 
Table 9: Placebo test

\begin{tabular}{|c|c|c|c|c|c|c|c|c|}
\hline & \multicolumn{4}{|c|}{ Opening } & \multicolumn{4}{|c|}{ Extension } \\
\hline & (1) & $(2)$ & $(3)$ & $(3 a)$ & (4) & $(5)$ & (6) & $(6 a)$ \\
\hline \multirow[t]{2}{*}{ MEA $\times$ After } & 0.028 & & 0.053 & & $-0.051^{*}$ & & -0.056 & \\
\hline & $(0.032)$ & & $(0.043)$ & & $(0.028)$ & & $(0.034)$ & \\
\hline \multirow[t]{2}{*}{ McEA $\times$ After } & & -0.009 & 0.040 & & & 0.044 & -0.007 & \\
\hline & & $(0.035)$ & $(0.046)$ & & & $(0.032)$ & $(0.037)$ & \\
\hline \multirow[t]{2}{*}{ MEA w/stations $\times$ After } & & & & 0.046 & & & & -0.028 \\
\hline & & & & $(0.032)$ & & & & $(0.039)$ \\
\hline \multirow[t]{2}{*}{ McEA w/stations $\times$ After } & & & & -0.079 & & & & -0.010 \\
\hline & & & & $(0.050)$ & & & & $(0.027)$ \\
\hline Covariates & $\mathrm{Y}$ & $\mathrm{Y}$ & $\mathrm{Y}$ & $\mathrm{Y}$ & $\mathrm{Y}$ & $\mathrm{Y}$ & $\mathrm{Y}$ & $\mathrm{Y}$ \\
\hline Time F.E. & $\mathrm{Y}$ & $\mathrm{Y}$ & $\mathrm{Y}$ & $\mathrm{Y}$ & $\mathrm{Y}$ & $\mathrm{Y}$ & $\mathrm{Y}$ & $\mathrm{Y}$ \\
\hline Municipalities F.E. & $\mathrm{Y}$ & $\mathrm{Y}$ & $\mathrm{Y}$ & Y & $\mathrm{Y}$ & $\mathrm{Y}$ & $\mathrm{Y}$ & $\mathrm{Y}$ \\
\hline$N$ & 5089 & 5089 & 5089 & 5089 & 5376 & 5376 & 5376 & 5376 \\
\hline$R^{2}$ & 0.825 & 0.825 & 0.825 & 0.825 & 0.815 & 0.815 & 0.815 & 0.815 \\
\hline
\end{tabular}

Standard errors in parentheses are clustered in the municipalities. Columns (1)-(4) are the results for the opening in 2004 . They use data for 2001 and 2007. Columns (5)-(8) are the results for the extension in 2011. They use data for 2008 and 2014 . $*$ $p<0.1,{ }^{* *} p<0.05,{ }^{* * *} p<0.01$

Table 10: Sub-sample Analysis 1 by zoning

\begin{tabular}{|c|c|c|c|c|c|c|c|c|}
\hline & \multicolumn{4}{|c|}{ Opening } & \multicolumn{4}{|c|}{ Extension } \\
\hline & (1) & $(2)$ & $(3)$ & $(4)$ & $(5)$ & $(6)$ & $(7)$ & $(8)$ \\
\hline \multirow[t]{2}{*}{ MEA w/stations $\times$ After } & $0.113^{* * *}$ & $0.174^{* * *}$ & 0.040 & -0.029 & $0.078^{* * *}$ & $0.065^{* * *}$ & $0.067^{* * *}$ & 0.020 \\
\hline & $(0.028)$ & $(0.036)$ & $(0.067)$ & $(0.037)$ & $(0.023)$ & $(0.023)$ & $(0.025)$ & $(0.042)$ \\
\hline \multirow[t]{2}{*}{ McEA w/stations $\times$ After } & 0.031 & $0.094^{*}$ & 0.033 & & -0.006 & -0.003 & 0.037 & 0.005 \\
\hline & $(0.027)$ & $(0.051)$ & $(0.056)$ & & $(0.023)$ & $(0.027)$ & $(0.053)$ & $(0.045)$ \\
\hline Covariates & $\mathrm{Y}$ & $\mathrm{Y}$ & $\mathrm{Y}$ & $\mathrm{Y}$ & $\mathrm{Y}$ & $\mathrm{Y}$ & $\mathrm{Y}$ & $\mathrm{Y}$ \\
\hline Time F.E. & $\mathrm{Y}$ & $\mathrm{Y}$ & $\mathrm{Y}$ & $\mathrm{Y}$ & $\mathrm{Y}$ & $\mathrm{Y}$ & $\mathrm{Y}$ & $\mathrm{Y}$ \\
\hline Municipalities F.E. & $\mathrm{Y}$ & $\mathrm{Y}$ & $\mathrm{Y}$ & $\mathrm{Y}$ & $\mathrm{Y}$ & $\mathrm{Y}$ & $\mathrm{Y}$ & $\mathrm{Y}$ \\
\hline$N$ & 5488 & 3315 & 1129 & 336 & 4740 & 2808 & 1020 & 281 \\
\hline$R^{2}$ & 0.815 & 0.790 & 0.842 & 0.782 & 0.830 & 0.792 & 0.874 & 0.770 \\
\hline
\end{tabular}

Standard errors in parentheses are clustered in the municipalities. Columns (1)-(4) are the results for the opening in 2004. They use data for 2001 and 2007. Columns (5)-(8) are the results for the extension in 2011. They use data for 2008 and 2014. Columns (1) and (5) are full sample analyses. Columns (2) and (6) are sub-sample analyses of residential use. Columns (3) and (7) are sub-sample analyses of commercial use. Columns (4) and (8) are sub-sample analyses of industrial use. ${ }^{*} p<0.1,{ }^{* *} p<0.05,{ }^{* * *} p<0.01$ 
Table 11: Sub-sample Analysis 2 by zoning

\begin{tabular}{|c|c|c|c|c|c|c|c|c|}
\hline & \multicolumn{4}{|c|}{ Opening } & \multicolumn{4}{|c|}{ Extension } \\
\hline & (1) & $(2)$ & (3) & (4) & (5) & $(6)$ & $(7)$ & (8) \\
\hline \multirow[t]{2}{*}{ Fukuoka MEA × After } & & & & & $0.096^{* * *}$ & $0.093^{* * *}$ & $0.051^{* *}$ & $0.063^{*}$ \\
\hline & & & & & $(0.024)$ & $(0.023)$ & $(0.022)$ & $(0.035)$ \\
\hline \multirow[t]{2}{*}{ Kurume MEA $\times$ After } & & & & & $0.046^{* *}$ & 0.022 & 0.022 & -0.045 \\
\hline & & & & & $(0.023)$ & $(0.016)$ & $(0.030)$ & $(0.053)$ \\
\hline \multirow[t]{2}{*}{ Omuta MEA $\times$ After } & & & & & -0.060 & $-0.077^{* *}$ & 0.036 & $-0.068^{* *}$ \\
\hline & & & & & $(0.037)$ & $(0.031)$ & $(0.073)$ & $(0.031)$ \\
\hline \multirow[t]{2}{*}{ Kumamoto MEA $\times$ After } & & & & & $0.066^{* * *}$ & $0.056^{* * *}$ & $0.041^{*}$ & 0.060 \\
\hline & & & & & $(0.021)$ & $(0.017)$ & $(0.024)$ & $(0.038)$ \\
\hline \multirow[t]{2}{*}{ Yatsushiro MEA $\times$ After } & $-0.080^{* * *}$ & -0.034 & $-0.147^{* * *}$ & & $-0.072^{* * *}$ & $-0.138^{* * *}$ & -0.016 & \\
\hline & $(0.018)$ & $(0.023)$ & $(0.049)$ & & $(0.024)$ & $(0.031)$ & $(0.033)$ & \\
\hline \multirow[t]{2}{*}{ Kagoshima MEA $\times$ After } & $0.132^{* * *}$ & $0.196^{* * *}$ & 0.071 & -0.029 & $0.061^{* *}$ & 0.037 & $0.117^{* * *}$ & $-0.119^{* * *}$ \\
\hline & $(0.015)$ & $(0.022)$ & $(0.051)$ & $(0.037)$ & $(0.026)$ & $(0.031)$ & $(0.037)$ & $(0.032)$ \\
\hline \multirow[t]{2}{*}{ Tosu McEA $\times$ After } & & & & & 0.011 & 0.005 & $0.168^{* * *}$ & 0.004 \\
\hline & & & & & $(0.027)$ & $(0.048)$ & $(0.020)$ & $(0.046)$ \\
\hline \multirow[t]{2}{*}{ Tamana McEA $\times$ After } & & & & & -0.018 & -0.020 & 0.016 & \\
\hline & & & & & $(0.015)$ & $(0.013)$ & $(0.034)$ & \\
\hline \multirow[t]{2}{*}{ Minamata McEA $\times$ After } & $-0.055^{* * *}$ & 0.011 & -0.012 & & $-0.045^{* * *}$ & -0.003 & $-0.084^{* * *}$ & \\
\hline & $(0.018)$ & $(0.022)$ & $(0.045)$ & & $(0.011)$ & $(0.012)$ & $(0.020)$ & \\
\hline \multirow[t]{2}{*}{ Satsumasendai McEA $\times$ After } & $0.048^{*}$ & $0.112^{*}$ & 0.046 & & -0.035 & -0.022 & -0.024 & \\
\hline & $(0.027)$ & $(0.059)$ & $(0.062)$ & & $(0.024)$ & $(0.019)$ & $(0.048)$ & \\
\hline Covariates & $\mathrm{Y}$ & $\mathrm{Y}$ & $\mathrm{Y}$ & $\mathrm{Y}$ & $\mathrm{Y}$ & $\mathrm{Y}$ & $\mathrm{Y}$ & $\mathrm{Y}$ \\
\hline Time F.E. & $\mathrm{Y}$ & $\mathrm{Y}$ & $\mathrm{Y}$ & $\mathrm{Y}$ & $\mathrm{Y}$ & $\mathrm{Y}$ & $\mathrm{Y}$ & $\mathrm{Y}$ \\
\hline Municipalities F.E. & $\mathrm{Y}$ & $\mathrm{Y}$ & $\mathrm{Y}$ & $\mathrm{Y}$ & $\mathrm{Y}$ & $\mathrm{Y}$ & $\mathrm{Y}$ & $\mathrm{Y}$ \\
\hline$N$ & 5488 & 3315 & 1129 & 336 & 4370 & 2631 & 931 & 279 \\
\hline$R^{2}$ & 0.815 & 0.790 & 0.843 & 0.782 & 0.825 & 0.770 & 0.868 & 0.771 \\
\hline
\end{tabular}

Standard errors in parentheses are clustered in the municipalities. Columns (1)-(4) are the results for the opening in 2004 . They use data for 2001 and 2007. Columns (5)-(8) are the results for the extension in 2011. They use data for 2008 and 2014. Columns (1) and (5) are full sample analyses. Columns (2) and (6) are sub-sample analyses of residential use. Columns (3) and (7) are sub-sample analyses of commercial use. Columns (4) and (8) are sub-sample analyses of industrial use. ${ }^{*} p<0.1,{ }^{* *} p<0.05,{ }^{* * *} p<0.01$ 
Table 12: Dynamic effects

\begin{tabular}{|c|c|c|c|c|c|}
\hline & \multicolumn{2}{|c|}{ Partial Opening } & & \multicolumn{2}{|c|}{ Whole Opening } \\
\hline & MEA & McEA & & MEA & McEA \\
\hline DID estimators & & & DID estimators & & \\
\hline 2001 & $\begin{array}{c}0.0217^{* * *} \\
\quad(6.55)\end{array}$ & $\begin{array}{c}-0.00123 \\
(-0.10)\end{array}$ & 2008 & $\begin{array}{c}0.0279 \\
(1.89)\end{array}$ & $\begin{array}{c}-0.00454 \\
(-0.83)\end{array}$ \\
\hline 2002 & $\begin{array}{c}0.0378^{* * *} \\
\quad(5.37)\end{array}$ & $\begin{array}{c}0.0221 \\
(1.69)\end{array}$ & 2009 & $\begin{array}{c}0.0301^{*} \\
(2.09)\end{array}$ & $\begin{array}{c}-0.00798 \\
(-0.98)\end{array}$ \\
\hline 2003 & $\begin{array}{c}0.0421^{* *} \\
(3.28)\end{array}$ & $\begin{array}{c}0.0368^{*} \\
(2.26)\end{array}$ & 2010 & $\begin{array}{c}0.0278^{*} \\
(2.02)\end{array}$ & $\begin{array}{c}-0.00981 \\
(-0.82)\end{array}$ \\
\hline 2004 & $\begin{array}{c}0.0764^{* * *} \\
\quad(4.60)\end{array}$ & $\begin{array}{c}0.0752^{* * *} \\
(3.98)\end{array}$ & 2011 & $\begin{array}{c}0.0358 \\
(1.94)\end{array}$ & $\begin{array}{c}0.000620 \\
(0.03)\end{array}$ \\
\hline 2005 & $\begin{array}{c}0.0791^{* * *} \\
\quad(3.53)\end{array}$ & $\begin{array}{c}0.0265 \\
(0.96)\end{array}$ & 2012 & $\begin{array}{c}0.0501^{*} \\
(2.25)\end{array}$ & $\begin{array}{c}-0.00578 \\
(-0.27)\end{array}$ \\
\hline 2006 & $\begin{array}{c}0.110^{* * *} \\
(4.27)\end{array}$ & $\begin{array}{c}0.0435 \\
(1.43)\end{array}$ & 2013 & $\begin{array}{c}0.0781^{* *} \\
(2.67)\end{array}$ & $\begin{array}{c}-0.00521 \\
(-0.23)\end{array}$ \\
\hline 2007 & $\begin{array}{c}0.136^{* * *} \\
(4.80)\end{array}$ & $\begin{array}{c}0.0294 \\
(0.88)\end{array}$ & 2014 & $\begin{array}{c}0.106^{* *} \\
(2.93)\end{array}$ & $\begin{array}{c}-0.00993 \\
(-0.38)\end{array}$ \\
\hline 2008 & $\begin{array}{c}0.141^{* * *} \\
(4.53)\end{array}$ & $\begin{array}{c}0.0231 \\
(0.66)\end{array}$ & 2015 & $\begin{array}{c}0.128^{* *} \\
(3.01)\end{array}$ & $\begin{array}{c}-0.0158 \\
(-0.53)\end{array}$ \\
\hline 2009 & $\begin{array}{c}0.162^{* * *} \\
(4.92)\end{array}$ & $\begin{array}{c}0.0218 \\
(0.59)\end{array}$ & 2016 & $\begin{array}{c}0.148^{* *} \\
(2.93)\end{array}$ & $\begin{array}{c}-0.0247 \\
(-0.69)\end{array}$ \\
\hline$N$ & 27355 & 27355 & $N$ & 23742 & 23742 \\
\hline$R^{2}$ & 0.814 & 0.814 & $R^{2}$ & 0.830 & 0.830 \\
\hline
\end{tabular}

Standard errors in parentheses are clustered in the municipalities. The analysis for the opening in 2004 uses data for 2001 and 2007. The analysis for the extension in 2011 uses data for 2008 and 2014. Each value shows the estimated coefficient of MEA w/stations dummy (or McEA w/stations dummy) $\times$ After $\times$ a certain year dummy. ${ }^{*} p<0.1,{ }^{* *} p<0.05,{ }^{* * *} p<0.01$ 
Table 13: Trains types on the Kagoshima route

\begin{tabular}{|c|c|c|c|c|}
\hline & & \multicolumn{3}{|c|}{ Train Types } \\
\hline & & Mizuho & Sakura & Tsubame \\
\hline Hakata St. & Fukuoka MEA & $\bullet$ & $\bullet$ & $\bullet$ \\
\hline Shin-Tosu St. & Tosu McEA & & $\bullet$ & $\bullet$ \\
\hline Kurume St. & Kurume MEA & & $\bullet$ & $\bullet$ \\
\hline Chikugo-Funagoya St. & Kurume MEA & & & $\bullet$ \\
\hline Shin-Omuta St. & Omuta MEA & & & $\bullet$ \\
\hline Shin-Tamana St. & Tamana McEA & & & $\bullet$ \\
\hline Kumamoto St. & Kumamoto MEA & $\bullet$ & $\bullet$ & $\bullet$ \\
\hline Shin-Yatsuhshiro St. & Yatsushiro MEA & & $\circ$ & $\bullet$ \\
\hline Shin-Minamata St. & Minamata McEA & & $\circ$ & $\bullet$ \\
\hline Izumi St. & & & $\circ$ & $\bullet$ \\
\hline Sendai St. & Satsumasendai McEA & & $\bullet$ & $\bullet$ \\
\hline Kagoshima-Chuo St. & Kagoshima MEA & $\bullet$ & $\bullet$ & $\bullet$ \\
\hline
\end{tabular}

•: served by all trains, •: served by some trains. Source: Kyushu Railway Company Timetable (access: 2018/8/7) (https://www.jrkyushu-timetable.jp/cgi-bin/sp/sp-tt_dep.cgi/2862600/) 
Table 14: Analysis 1 with train type dummies

\begin{tabular}{lcc}
\hline \hline & $(1)$ & $(2)$ \\
\hline MEA $\times$ After & $0.096^{* * *}$ & $0.063^{* *}$ \\
& $(0.028)$ & $(0.026)$ \\
McEA $\times$ After & 0.017 & 0.010 \\
& $(0.030)$ & $(0.032)$ \\
three types dummy $\times$ MEA $\times$ After & & $0.079^{* * *}$ \\
& & $(0.020)$ \\
two types dummy $\times$ MEA $\times$ After & & $0.042^{*}$ \\
& & $(0.023)$ \\
two types dummy $\times$ McEA $\times$ After & & 0.037 \\
& & $(0.032)$ \\
Covariates & $\mathrm{Y}$ & $\mathrm{Y}$ \\
Time F.E. & $\mathrm{Y}$ & $\mathrm{Y}$ \\
Municipalities F.E. & $\mathrm{Y}$ & $\mathrm{Y}$ \\
\hline$N$ & 4740 & 4740 \\
$R^{2}$ & 0.830 & 0.830 \\
\hline \hline
\end{tabular}

\begin{tabular}{lcc}
\hline \hline & $(3)$ & $(4)$ \\
\hline MEA w/stations $\times$ After & $0.078^{* * *}$ & $-0.056^{*}$ \\
& $(0.023)$ & $(0.030)$ \\
McEA w/stations $\times$ After & -0.006 & -0.017 \\
& $(0.023)$ & $(0.018)$ \\
three types dummy $\times$ MEA w/stations $\times$ After & & $0.148^{* * *}$ \\
& & $(0.032)$ \\
two types dummy $\times$ MEA w/stations $\times$ After & & $0.111^{* * *}$ \\
& & $(0.033)$ \\
two types dummy $\times$ McEA w/stations $\times$ After & & 0.014 \\
& & $(0.027)$ \\
Covariates & $\mathrm{Y}$ & $\mathrm{Y}$ \\
Time F.E. & $\mathrm{Y}$ & $\mathrm{Y}$ \\
Municipalities F.E. & $\mathrm{Y}$ & $\mathrm{Y}$ \\
\hline$N$ & 4740 & 4740 \\
$R^{2}$ & 0.830 & 0.830 \\
\hline \hline Standard errors in parentheses are clustered in the municipalities. All columns show the results \\
for the extension in 2011. They use data for 2008 and 2014. ${ }^{*} p<0.1,{ }^{* *} p<0.05,{ }^{* * *} p<0.01$
\end{tabular}




\section{Appendices}

\section{Appendix A: Results for the Control Variables}

\begin{tabular}{|c|c|c|c|c|c|c|c|c|}
\hline & \multicolumn{4}{|c|}{ Opening } & \multicolumn{4}{|c|}{ Extension } \\
\hline & $(1)$ & $(2)$ & $(3)$ & $(4)$ & $(5)$ & $(6)$ & $(7)$ & (8) \\
\hline \multirow[t]{2}{*}{ Constant } & $9.829^{* * *}$ & $9.828^{* * *}$ & $9.827^{* * *}$ & $9.835^{* * *}$ & $9.914^{* * *}$ & $9.942^{* * *}$ & $9.942^{* * *}$ & $9.913^{* * *}$ \\
\hline & $(0.176)$ & $(0.176)$ & $(0.175)$ & $(0.182)$ & $(0.159)$ & $(0.159)$ & $(0.159)$ & $(0.156)$ \\
\hline \multirow[t]{2}{*}{ Distance from the nearest station } & $-0.003^{* * *}$ & $-0.003^{* * *}$ & $-0.003^{* * *}$ & $-0.003^{* * *}$ & $-0.003^{* * *}$ & $-0.003^{* * *}$ & $-0.003^{* * *}$ & $-0.003^{* * *}$ \\
\hline & $(0.001)$ & $(0.001)$ & $(0.001)$ & $(0.001)$ & $(0.001)$ & $(0.001)$ & $(0.001)$ & $(0.001)$ \\
\hline \multirow[t]{2}{*}{ Acreage } & $-0.300^{* * *}$ & $-0.300^{* * *}$ & $-0.300^{* * *}$ & $-0.298^{* * *}$ & $-0.113^{* * *}$ & $-0.112^{* * *}$ & $-0.110^{* * *}$ & $-0.108^{* * *}$ \\
\hline & $(0.079)$ & $(0.078)$ & $(0.078)$ & $(0.079)$ & $(0.022)$ & $(0.022)$ & $(0.022)$ & $(0.022)$ \\
\hline \multirow[t]{2}{*}{ Building-area ratio } & $-0.002^{* * *}$ & $-0.002^{* * *}$ & $-0.002^{* * *}$ & $-0.002^{* * *}$ & $-0.008^{* * *}$ & $-0.008^{* * *}$ & $-0.008^{* * *}$ & $-0.009^{* * *}$ \\
\hline & $(0.000)$ & $(0.000)$ & $(0.000)$ & $(0.001)$ & $(0.002)$ & $(0.002)$ & $(0.002)$ & $(0.002)$ \\
\hline \multirow[t]{2}{*}{ Floor-area area } & $0.002^{* * *}$ & $0.002^{* * *}$ & $0.002^{* * *}$ & $0.002^{* * *}$ & $0.003^{* * *}$ & $0.003^{* * *}$ & $0.003^{* * *}$ & $0.003^{* * *}$ \\
\hline & $(0.000)$ & $(0.000)$ & $(0.000)$ & $(0.000)$ & $(0.001)$ & $(0.001)$ & $(0.001)$ & $(0.000)$ \\
\hline \multirow[t]{2}{*}{ Town planning area dummy } & $-0.324^{* * *}$ & $-0.327^{* * *}$ & $-0.327^{* * *}$ & $-0.309^{* * *}$ & $-0.203^{* *}$ & $-0.203^{* *}$ & $-0.201^{* *}$ & $-0.168^{* *}$ \\
\hline & $(0.066)$ & $(0.066)$ & $(0.066)$ & $(0.061)$ & $(0.092)$ & $(0.092)$ & $(0.092)$ & $(0.080)$ \\
\hline \multirow[t]{2}{*}{ Water dummy } & $0.246^{*}$ & $0.247^{*}$ & $0.247^{*}$ & $0.247^{*}$ & 0.193 & 0.193 & 0.193 & $0.229^{*}$ \\
\hline & $(0.127)$ & $(0.127)$ & $(0.127)$ & $(0.132)$ & $(0.123)$ & $(0.124)$ & $(0.123)$ & $(0.124)$ \\
\hline \multirow[t]{2}{*}{ Gas dummy } & $0.283^{* * *}$ & $0.282^{* * *}$ & $0.282^{* * *}$ & $0.282^{* * *}$ & $0.290^{* * *}$ & $0.290^{* * *}$ & $0.290^{* * *}$ & $0.285^{* * *}$ \\
\hline & $(0.033)$ & $(0.033)$ & $(0.033)$ & $(0.033)$ & $(0.030)$ & $(0.030)$ & $(0.030)$ & $(0.030)$ \\
\hline \multirow[t]{2}{*}{ Drain dummy } & $0.177^{* * *}$ & $0.179^{* * *}$ & $0.180^{* * *}$ & $0.172^{* * *}$ & $0.170^{* * *}$ & $0.169^{* * *}$ & $0.171^{* * *}$ & $0.172^{* * *}$ \\
\hline & $(0.025)$ & $(0.026)$ & $(0.026)$ & $(0.025)$ & $(0.032)$ & $(0.032)$ & $(0.031)$ & $(0.028)$ \\
\hline \multirow[t]{2}{*}{ Residential use } & $0.584^{* * *}$ & $0.580^{* * *}$ & $0.580^{* * *}$ & $0.593^{* * *}$ & $0.521^{* * *}$ & $0.521^{* * *}$ & $0.522^{* * *}$ & $0.528^{* * *}$ \\
\hline & $(0.063)$ & $(0.063)$ & $(0.063)$ & $(0.064)$ & $(0.068)$ & $(0.068)$ & $(0.068)$ & $(0.065)$ \\
\hline \multirow[t]{2}{*}{ Commercial use } & $1.041^{* * *}$ & $1.039^{* * *}$ & $1.039^{* * *}$ & $1.046^{* * *}$ & $0.876^{* * *}$ & $0.878^{* * *}$ & $0.879^{* * *}$ & $0.896^{* * *}$ \\
\hline & $(0.058)$ & $(0.058)$ & $(0.058)$ & $(0.058)$ & $(0.088)$ & $(0.088)$ & $(0.088)$ & $(0.087)$ \\
\hline \multirow[t]{2}{*}{ Industrial use } & $0.609^{* * *}$ & $0.605^{* * *}$ & $0.606^{* * *}$ & $0.616^{* * *}$ & $0.429^{* * *}$ & $0.429^{* * *}$ & $0.430^{* * *}$ & $0.431^{* * *}$ \\
\hline & $(0.063)$ & $(0.063)$ & $(0.063)$ & $(0.064)$ & $(0.079)$ & $(0.079)$ & $(0.079)$ & $(0.074)$ \\
\hline$N$ & 5488 & 5488 & 5488 & 5488 & 4740 & 4740 & 4740 & 4740 \\
\hline$R^{2}$ & 0.815 & 0.815 & 0.815 & 0.819 & 0.830 & 0.830 & 0.830 & 0.836 \\
\hline
\end{tabular}

Standard errors in parentheses are clustered in the municipalities. Column (1) - (4) are the results for the opening in 2004 . They use data for 2001 and 2007. Column (5) - (8) are the results for the extension in 2011. Column (1), (2), (5) and (6) show the estimated covariates of Column (3), (3a), (6) and (6a) in Table 4, respectively. Column (3) and (7) show the estimated covariates of Column (3) and (6) in Table 5, respectively. Column (4) shows the result of covariates in Table 6. Column (8) shows the result of covariates in Table 7. ${ }^{*} p<0.1,{ }^{* *} p<0.05,{ }^{* * *} p<0.01$ 